\title{
After the Cop21 Agreement: No Major Changes
}

\author{
Jan-Erik Lane ${ }^{1 *}$ \\ ${ }^{1}$ fellow with Public Policy Institute, Belgrade \\ *Jan-Erik Lane, E-mail: janeklane@gmail.com
}

\begin{abstract}
The concentration of CO2 in the atmosphere keeps increasing: 399.6 (Jan, 2015), 402.52 (Jan, 2016), 404.21 (March 2016) and 409 (April 2016). It is true that a few countries have managed to not only halt the increase in $\mathrm{CO} 2$ emissions but also decrease the emissions. But from a global point of view, the CO2 emissions stay at a very high level. The G20, responsible for some 80 per cent of CO2 emissions, do nothing, concentrating on traditional interstate issue like the Middle East, North Korea, the Ukraine and the South China Sea. Whereas all new data indicate the dire consequences of climate change, business goes on as usual: more cars, trucks and buses, bigger engines, more aeroplanes and airports, bigger ships and larger container vessels, longer routes, new coal power stations, closing of nuclear plants, delaying the use of new or temporarily stopped nuclear reactors, etc.
\end{abstract}

\section{Keywords}

Global warming: $+1.5,+2,+4,+6$, implementation of policies, developing countries, GHG:s and CO2s, advanced countries, halting emission growth, reducing emissions, country energy sources, eliminating coal and reducing petroleum, coal filtration

\section{Introduction}

What could be involved in a trade-off between reduction of greenhouse gases on the one hand and economic development or growth on the other hand? This article portrays this connection by means of figures on a few key countries. The closer the link between GDP and anthropogenic CO2 emissions is, the more painful or costly will the transition to a reduction of emissions be. Policy implementation is difficult to achieve (Pressman \& Wildavsky, 1973, 1984).

The global warming process is already going on and proceeds seemingly unstoppably, involving inter alia larger climate swings, deforestation, desertification, ocean acidification and rising sea levels. One does not really know whether it is an irreversible transformation of Planet Earth, or where it could be stopped: $+1.5,+2,+2.7,+4,+6$, or would end in a global catastrophe.

\section{Greenhouse Gases: The Co2:s}

Greenhouse gases (GHG) contribute to the so-called greenhouse effect, which boils down to continuous overall warming of the Planet Earth. Atmospheric gases trap electromagnetic radiation from the sun that would otherwise have been reflected back out into space. These greenhouse gases include: methane, 
nitrous oxide, carbon dioxide, hydro fluorocarbons (HFCs), per fluorocarbons (PFCs), and sulphur hexafluoride (SF6). But these gases make up only a small fraction of the gases of the atmosphere. Here we focus upon the CO2:s. Halting or reducing GHG emissions may effectively concentrate upon the $\mathrm{CO} 2$ :s stemming from the energy and transportations sectors, i.e., coal and petroleum. We quote:

"The four largest human sources of U.S. greenhouse gases in 2009 were energy, non-fuel use of fossil fuels, natural gas production, and cement manufacture, in descending order. Non-fuel, greenhouse gas-producing applications of fuels include industrial production like asphalt, lubricants, waxes and other. Emissions related to cement manufacture happen when limestone (calcium carbonate) is reacted with silica to make clinker, the lumps ground to make cement" (Retrieved from http://www.burnanenergyjournal.com/the-connection-between-greenhouse-gases-climate-change-and-g lobal-warming/).

As Figure 1 shows, the main focus of GHG control should be on the $\mathrm{CO} 2$ emissions.

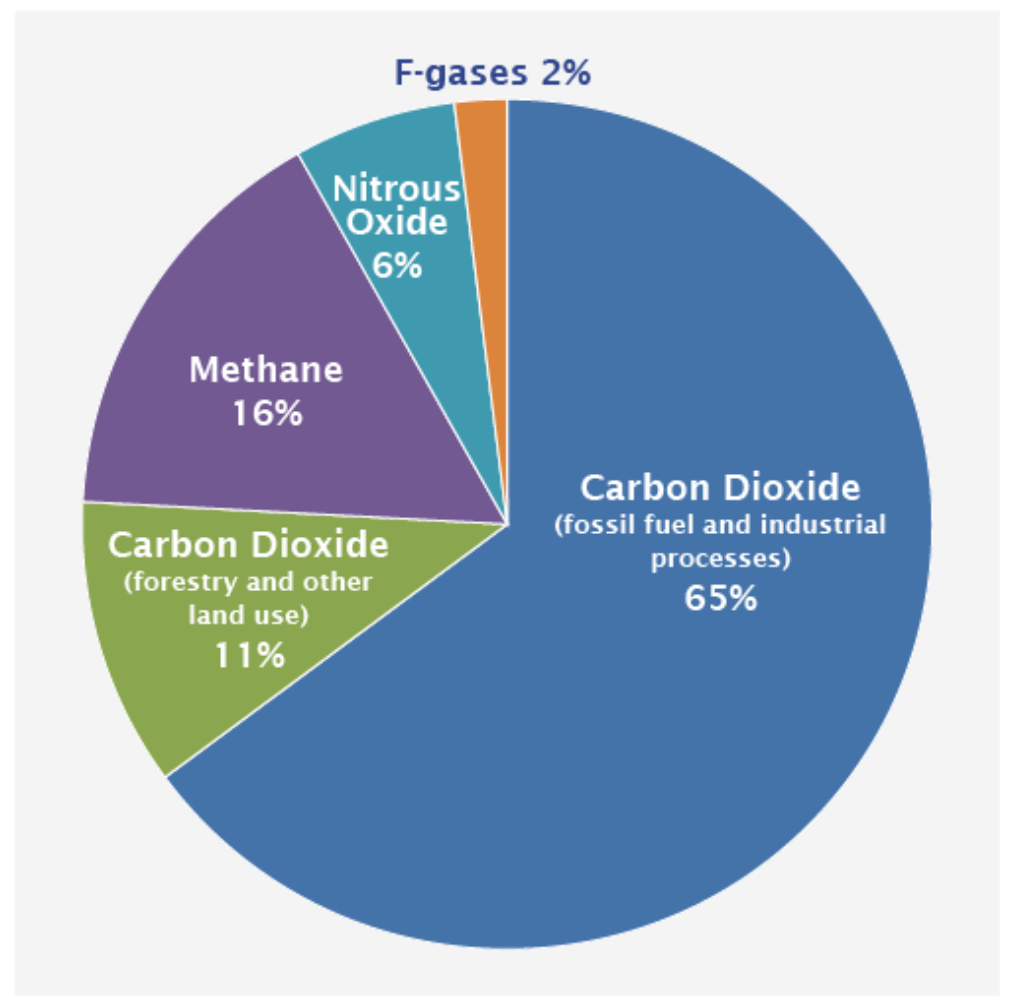

Figure 1. GHG:s from Global Gases

Source: IPCC (2014) based on global emissions from 2010. Details about the sources included in these estimates can be found in the Contribution of Working Group III to the Fifth Assessment Report of the Intergovernmental Panel on Climate Change.

GHG emissions have both natural and human sources. A global warming policy should target first and foremost the $\mathrm{CO} 2$ emissions from human activities. 


\section{Relevance of Energy Sources}

Fighting global warming involves reflecting upon several measures, as with the COP21 conference in Paris, including:

1) Slowing population growth,

2) Changing agricultural production modes,

3) Water recycling and waste treatment,

4) Ocean protection against waste and overfishing,

5) Changes in energy consumption: "decarbonisation",

6) Stopping deforestation and protecting rain forests,

7) Re-forestation or carbon capture, at source or in atmosphere.

Although energy is far from the only source of greenhouse gases, it is the single largest one. Energy use crops up in all forms of activities most often with an economic element: industry, transportation-land, sea, air, housing and commerce as well as food production and agriculture.

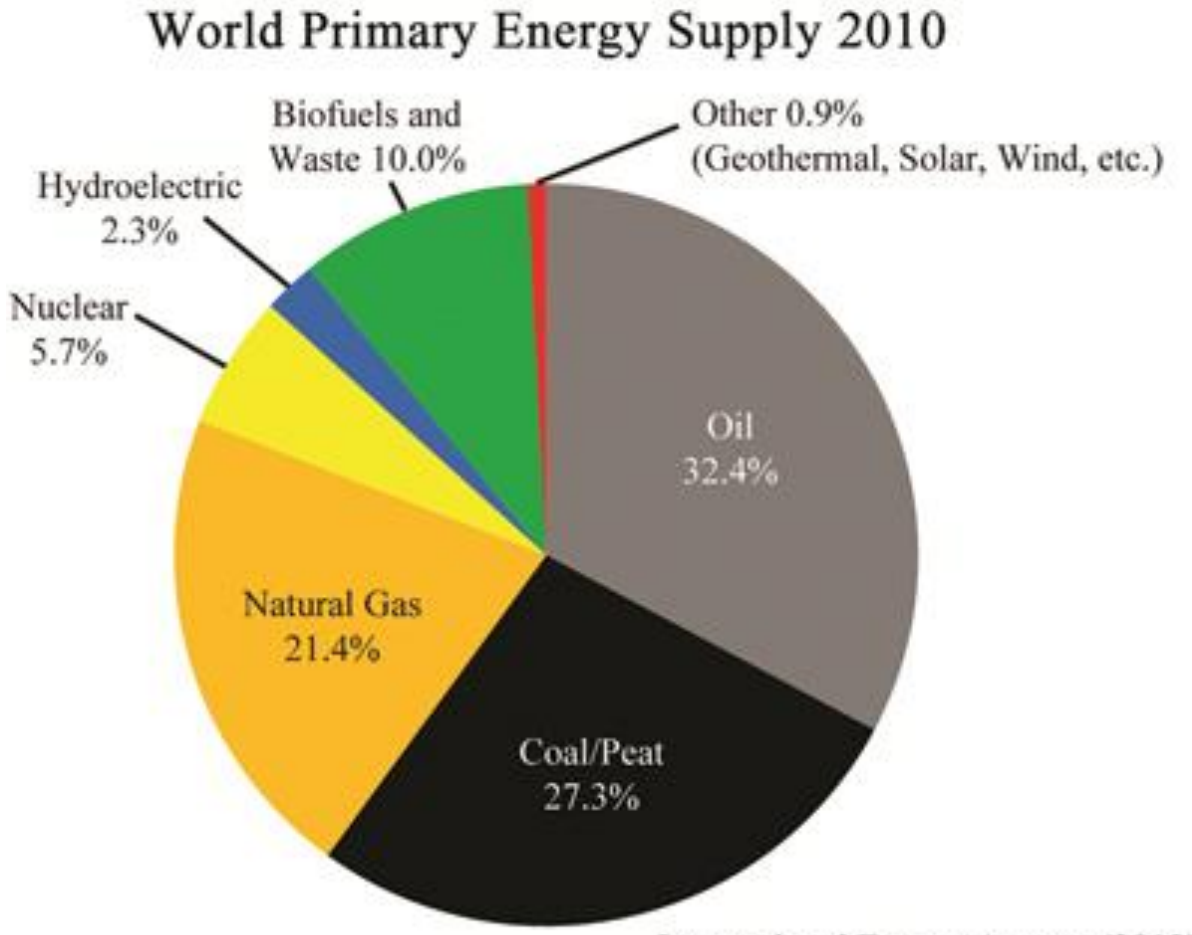

International Energy Agency (2012)

Figure 2. World Primary Energy Supply

Globally speaking, more than 80 per cent of the energy consumed daily is derived from the burning of fossil fuels. How fast can this be changed and what could be the economic costs of decarbonisation? Countries can attempt to meet their obligations in the COP21 Agreement by decarbonisation, lower economic growth or more energy efficiency. New technology and innovations will be crucial, not only 
in small scale endeavours but used massively. We wish to find out below is how countries vary in terms of their energy consumption. But consider first which energy source is most polluting-see Table 1.

Table 1. Energy Types and CO2:s: Pounds of $\mathrm{CO} 2$ Emitted per Million British Thermal Units (Btu) of Energy for Various Fuels

\begin{tabular}{lc}
\hline Coal (anthracite) & 228.6 \\
\hline Coal (bituminous) & 205.7 \\
Coal (lignite) & 215.4 \\
Coal (subbituminous) & 214.3 \\
Diesel fuel and heating oil & 161.3 \\
Gasoline & 157.2 \\
Propane & 139.0 \\
Natural gas & 117.0 \\
\hline
\end{tabular}

Source: http://www.eia.gov/tools/faqs/faq.cfm?id=73\&t=11

The main implications from Table 1 are that the use of coal in electricity generation must be reduced, old stations closed, and still operating coal power stations be equipped with filters for carbon capture. Moreover, the employment of petroleum products must be decreased in transportations: land, sea and air.

\section{Decarbonisation and Economic Growth}

Jeffrey Sachs has launched a coherent call for the world to move towards sustainable development, based on decarbonisation of the energy systems of countries (Retrieved from http://www.jeffsachs.org/2015/08/sustainable-development-for-humanitys-future/). He has correctly emphasized the close link between economic development or growth and the massive use of fossil fuels as energy sources during the last 20 years, resulting in the enormous expansion of GHG emissions. Ideally, a country would wish to start reducing its emissions of GHG:s without any major impact upon the GDP. This would require a policy mix of promoting energy efficiency, moving towards the use of renewables massively and cutting back upon fossil fuels.

Given this close link between GDP and energy consumption, how can the countries of the world achieve decarbonisation without hampering economic development or growth? What is the country link between GDP and $\mathrm{CO} 2$ emissions? It depends upon the nation in question! 
It is true that the stronger or closer the link between CO2:s and GDP is, the fewer the degrees of freedom in policy-making when it comes to decarbonisation and economic development or growth. Let me give a few telling country examples.

\section{Some Developing Countries}

One may find that the emissions of $\mathrm{CO} 2$ :s follows economic development closely in many countries. The basic explanation is population growth and GDP growth-more people and higher life style demands. Take the case of China, whose emissions are the largest in the world, totally speaking (Figure $3)$.

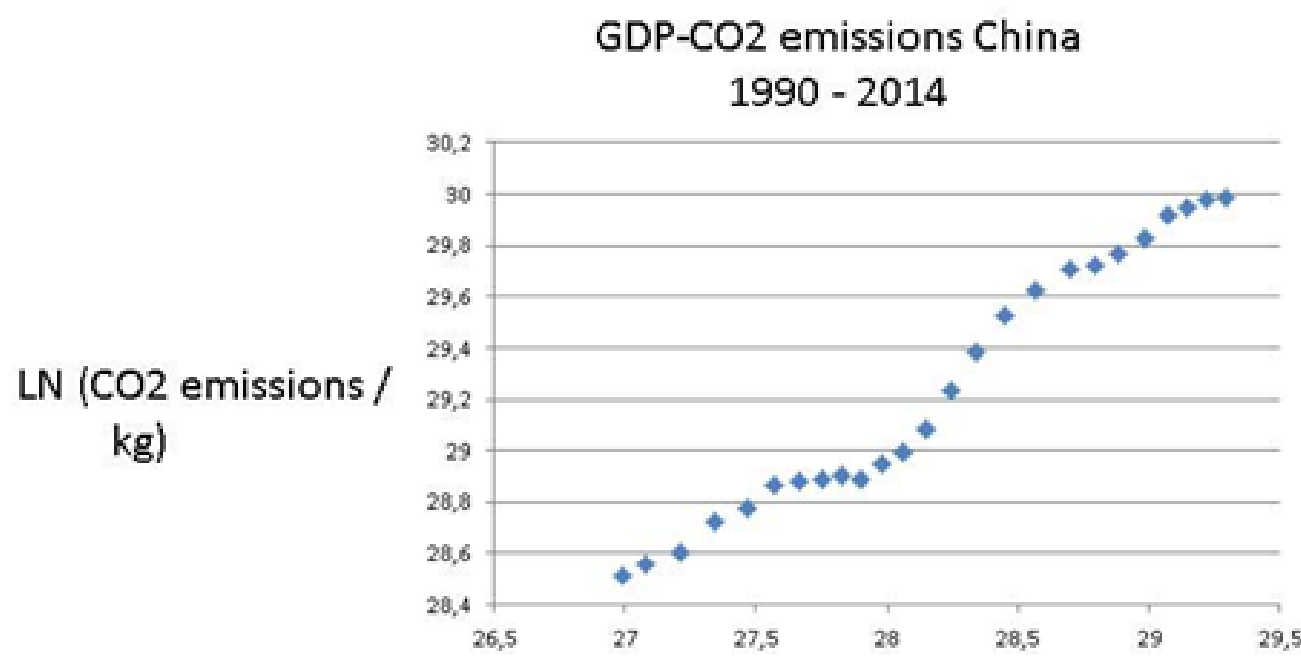

\section{LN (GDP / Constant Value 2005 USD)}

Figure 3. China: LN (CO2/Kg and LN (GDP/Constant Value 2005 USD) $\left(y=0.7 x ; R^{2}=0.97\right)$

The sharp increase in $\mathrm{CO} 2$ :s in China reflects not only the immensely rapid industrialization and urbanization of the last 30 years, but also its problematic energy mix (Figure 4). 


\title{
China energy consumption 2014
}

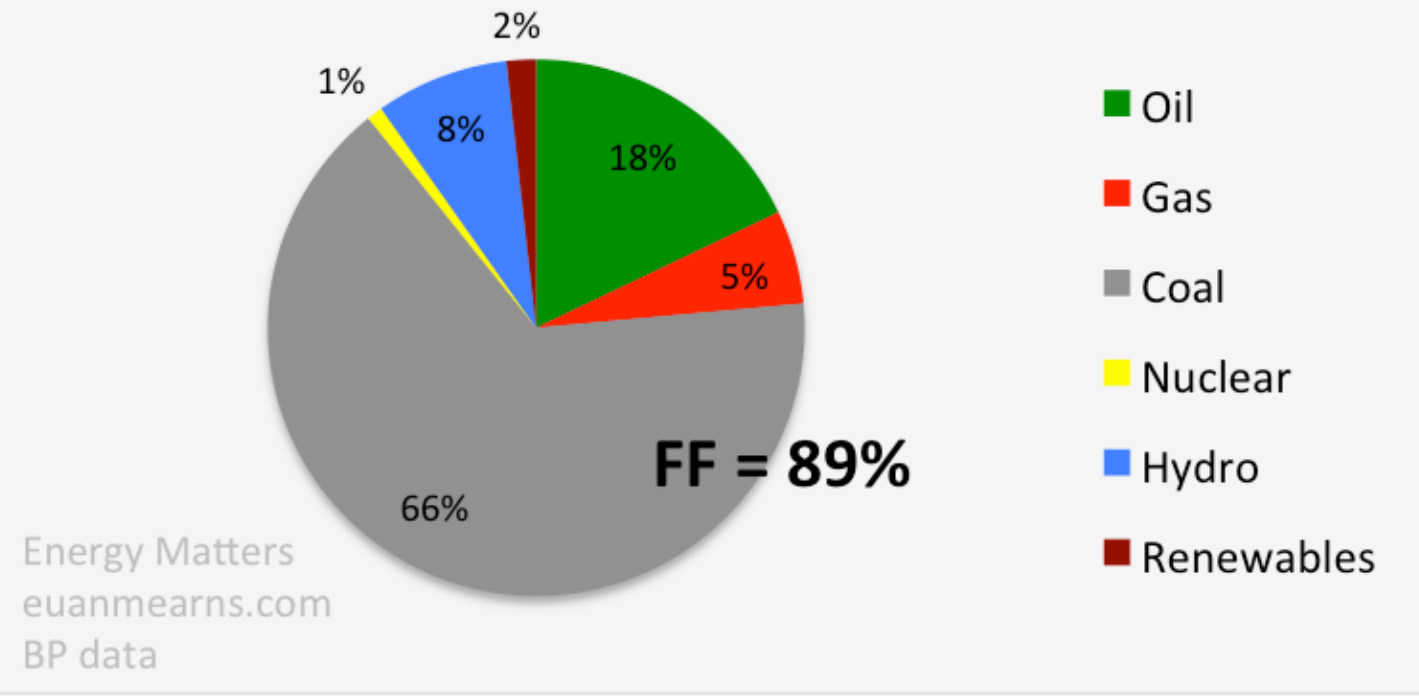

Figure 4. Total Energy Consumption in China

\begin{abstract}
Almost 70 per cent of the energy consumption comes from the burning of coal with an additional 20 per cent from other fossil fuels. The role of hydro and other renewable energy sources is small. But China is increasingly turning to atomic power. This energy mix makes China very vulnerable to demands for cutting $\mathrm{CO} 2$ emissions: other energy sources or massive installation of highly improved filters?

It should be pointed out that several small countries have much higher emissions per capita than China. This raises the enormously difficult problematic of fair cuts of emissions. Should the largest polluters per capita cut most or the biggest aggregate polluters? At COP21 this issue was resolved by the creation of a super fund to assist energy transition and environment protection in developing counties, as proposed by economist Stern (2007).

India will certainly appeal to the same problematic, namely per capita or aggregate emissions. The country is even more negative than China to cut $\mathrm{CO} 2$ emissions, as it is in an earlier stage of industrialization and urbanization. Figure 5 shows the close connection between emissions and GDP for this giant nation.
\end{abstract}




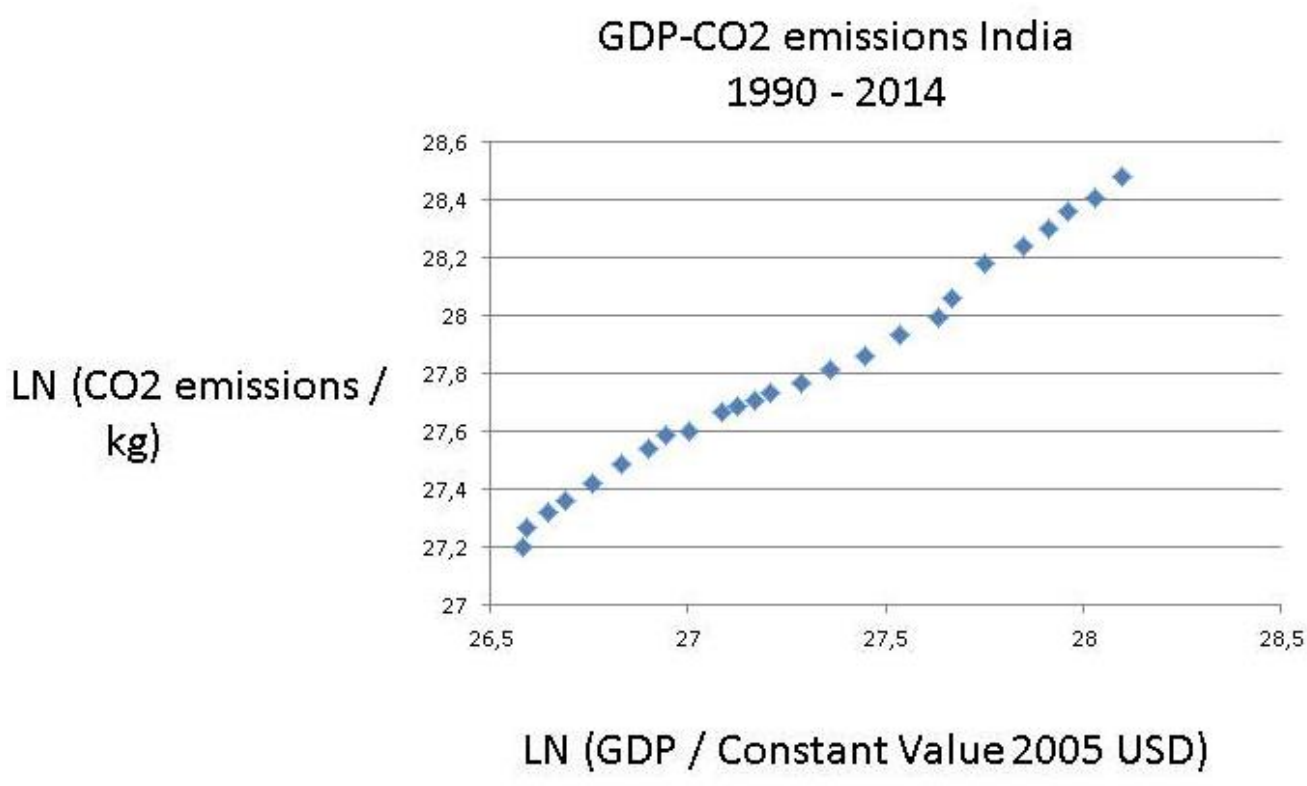

Figure 5. India: LN (CO2/Kg and LN (GDP/Constant Value 2005 USD)

India needs cheap energy for its industries, transportation and heating (Figure 5) as well as electrification. From where will it come? India has water power and nuclear energy, but relies most upon coal, oil and gas as power source. It has strong ambitions for the future expansion of energy, but how is it to be generated, the world asks. India actually has one of smallest numbers for energy per capita, although it produces much energy totally. Figure 6 shows its energy mix where renewables play a bigger role than in China.

\section{Figure 1.4 $\triangleright$ Primary energy demand in India by fuel}
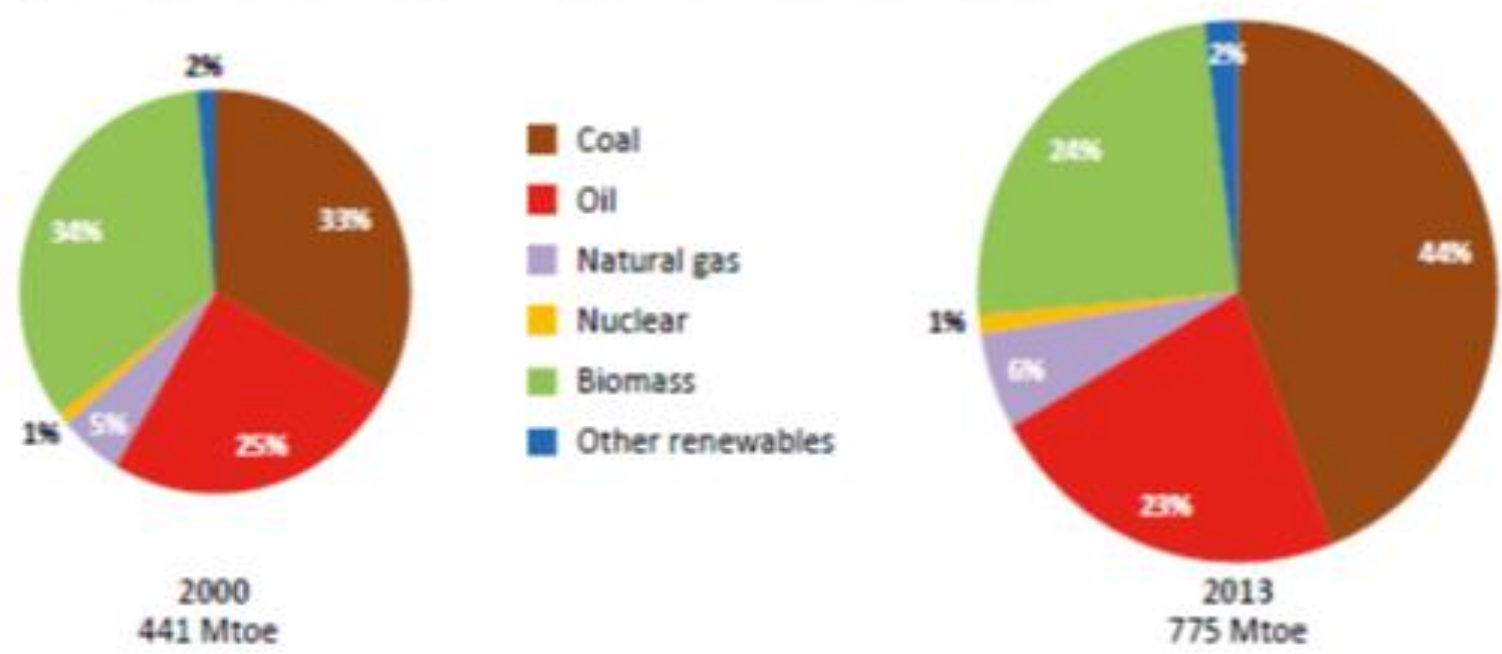

Figure 6. Total Energy Consumption in India 
India needs especially electricity, as 300 million inhabitants lack access to it. The country is heavily dependent upon fossil fuels (70 per cent), although to a less extent than China. Electricity can be generated by hydro power and nuclear power, both of which India employs. Yet, global warming reduces the capacity of hydro power and nuclear power meets with political resistance. Interestingly, India uses much biomass and waste for electricity production, which does not always reduce $\mathrm{CO} 2$ emissions. India's energy policy will be closely watched by other governments and NGO:s after 2018. One may guess correctly that countries that try hard to "catch-up" will have increasing emissions. This was true of China and India. Let us look at three more examples, like e.g., giant Indonesia-now the fourth largest emitter of $\mathrm{CO} 2$ :s in the world.

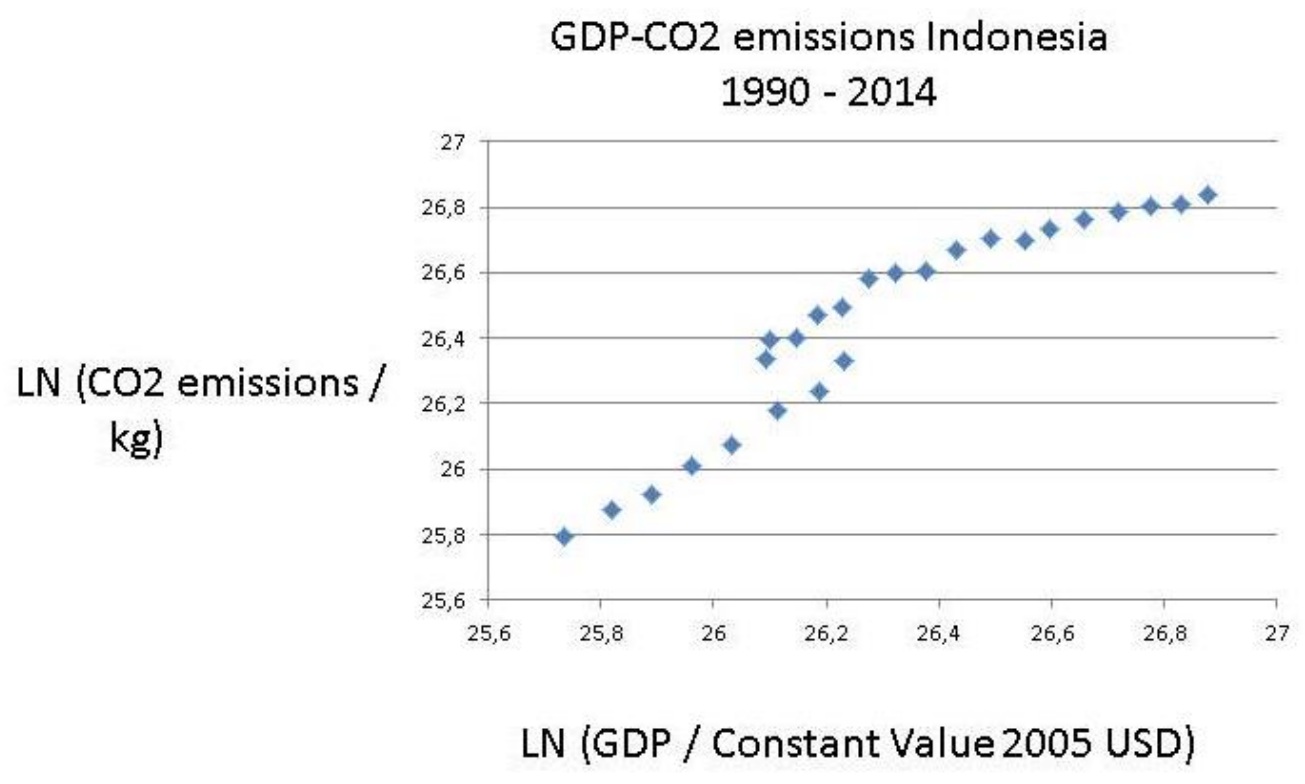

Figure 7. Indonesia: LN (CO2/Kg and LN (GDP/Constant Value 2005 USD)

Indonesia is a coming giant, both economically and sadly in terms of pollution. Figure 8 reminds of the upward trend for China and India. However, matters are even worse for Indonesia, as the burning of the rain forest on Kalimantan augments the $\mathrm{CO} 2$ emissions very much. Figure 8 presents the energy mix for this huge country in terms of population and territory. 


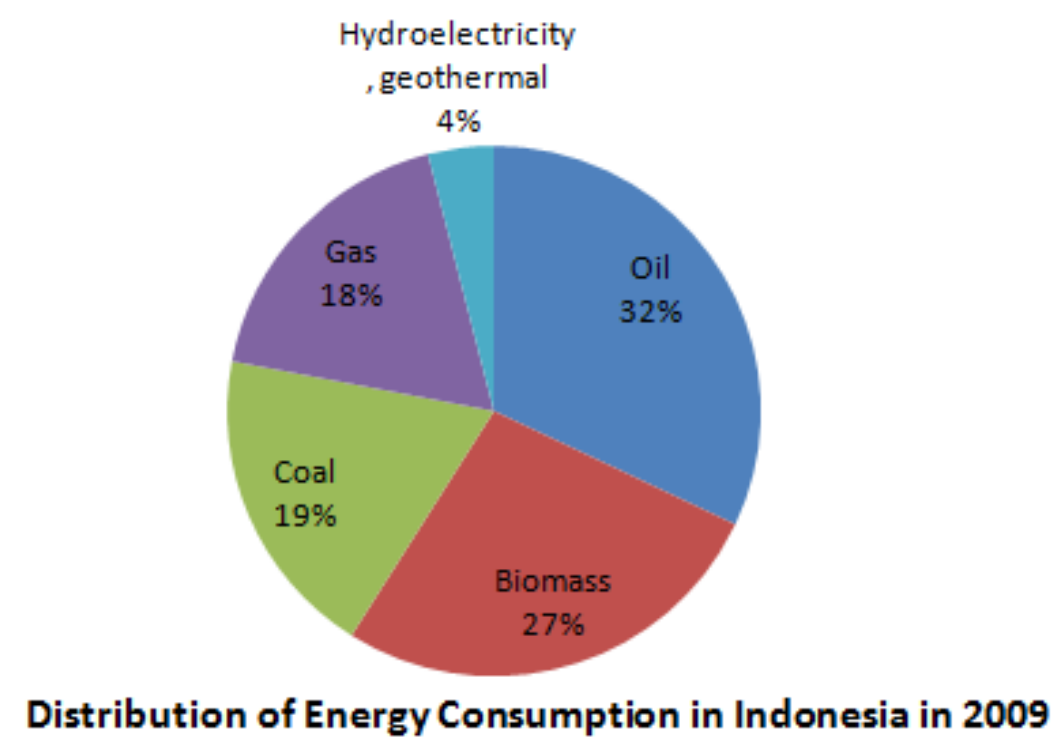

Figure 8. Distribution of Energy Consumption in Indonesia

Note: Retrieved from http://www.missrifka.com/energy-issue/recent-energy-status-in-indonesia.html

Only 4 per cent comes from hydro power with 70 per cent from fossil fuels and the remaining 27 per cent from biomass, which alas also pollutes.

The same upward trend holds for another major developing country with huge population, namely Pakistan (Figure 9).

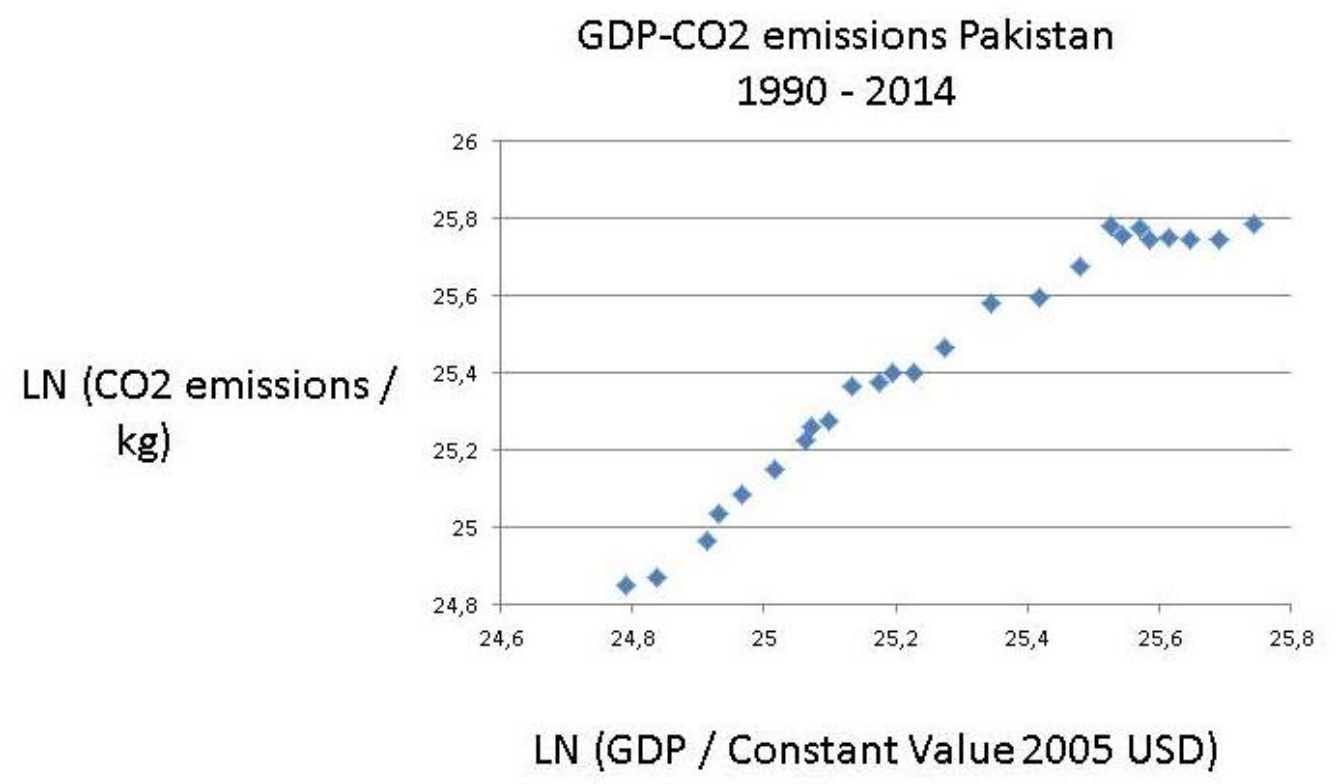

Figure 9. Pakistan: LN (CO2/Kg and LN (GDP/Constant Value 2005 USD) $\left(y=1.05 x-0.97 ; R^{2}=\right.$ 0.96) 
The amount of $\mathrm{CO} 2$ emissions is high for Pakistan, viewed as aggregate. Pakistan is mainly reliant upon fossil fuels (Figure 10).

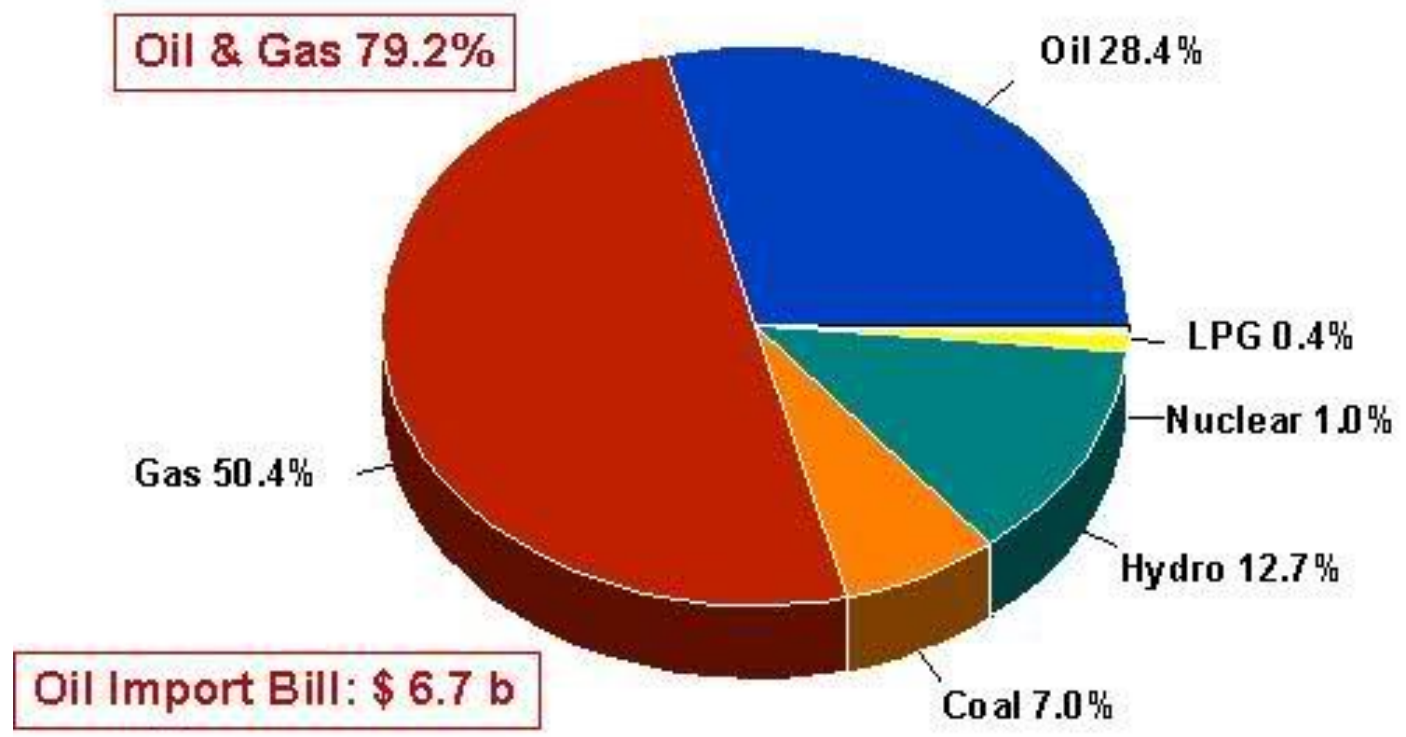

Figure 10. Pakistan Energy Consumption

Note: by ShoXee: http:www.//i27.tinypic.com/2h6cyag.jpg

But Pakistan employs a considerable portion of hydropower-13 per cent-and a minor portion of nuclear power. 
GDP vs. CO2 emissions Thailand 1990-2014

LN

(CO2 emissions $/ \mathrm{kg}$ )

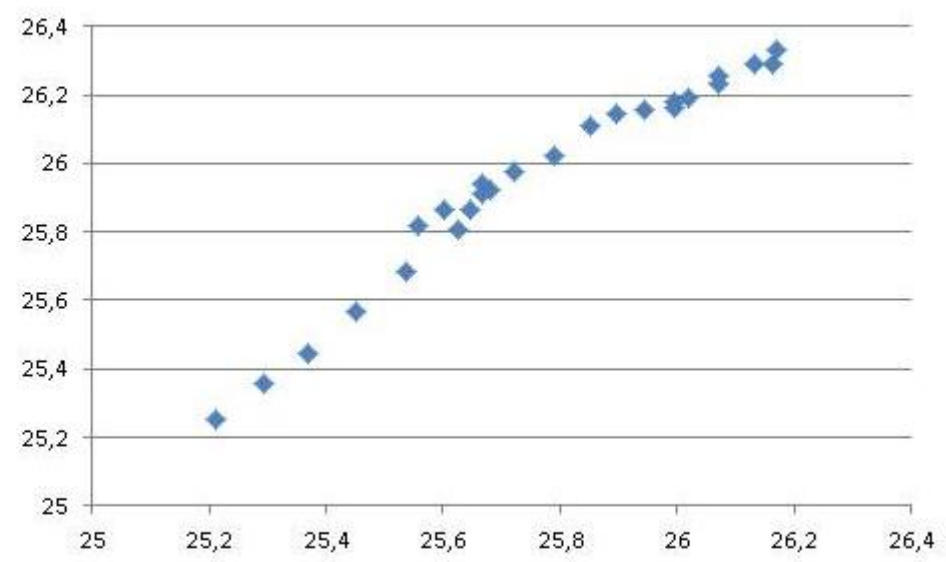

LN (GDP / (Constant Value 2005 USD))

Figure 11. Thailand $\left(y=1.07 x ; R^{2}=0.96\right)$

Total energy consumption in Thailand, by type (2010)

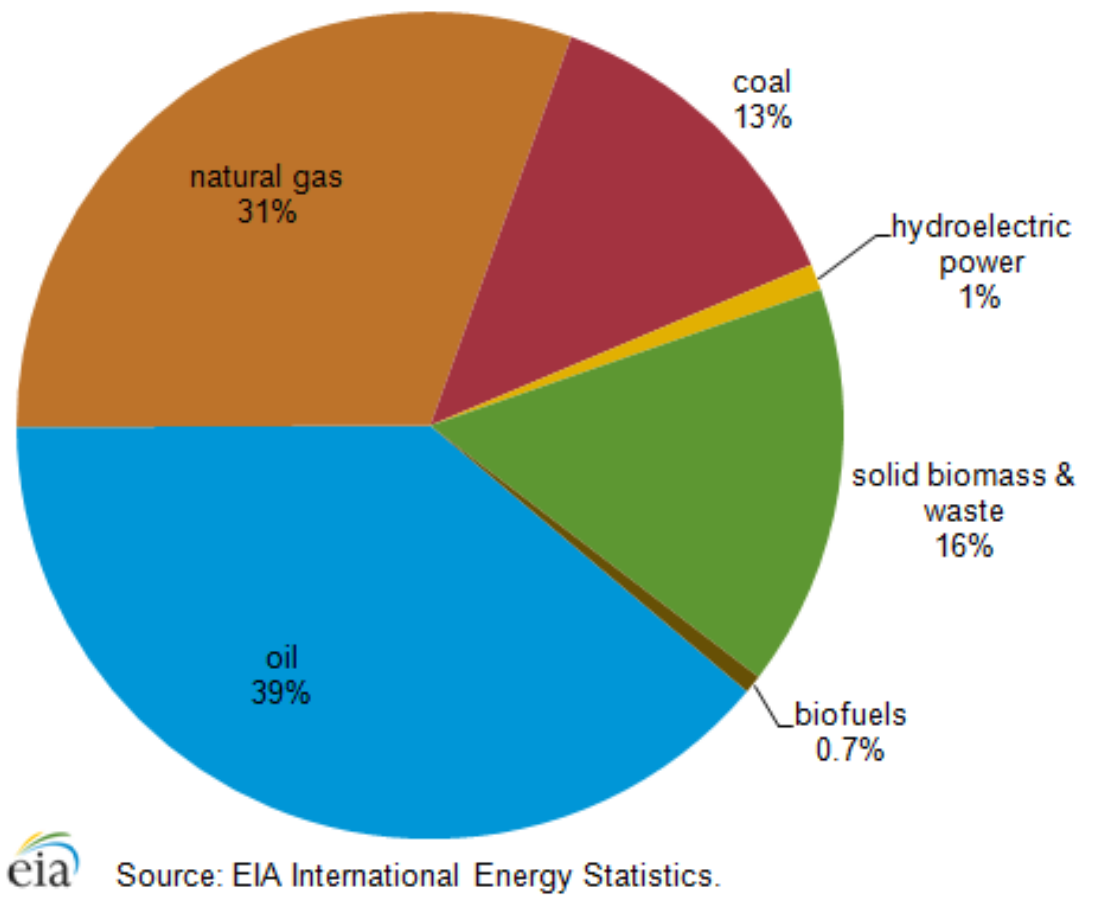

Figure 12. Total Energy Consumption in Thailand 
GDP vs. CO2 emissions Malaysia 1990-2014
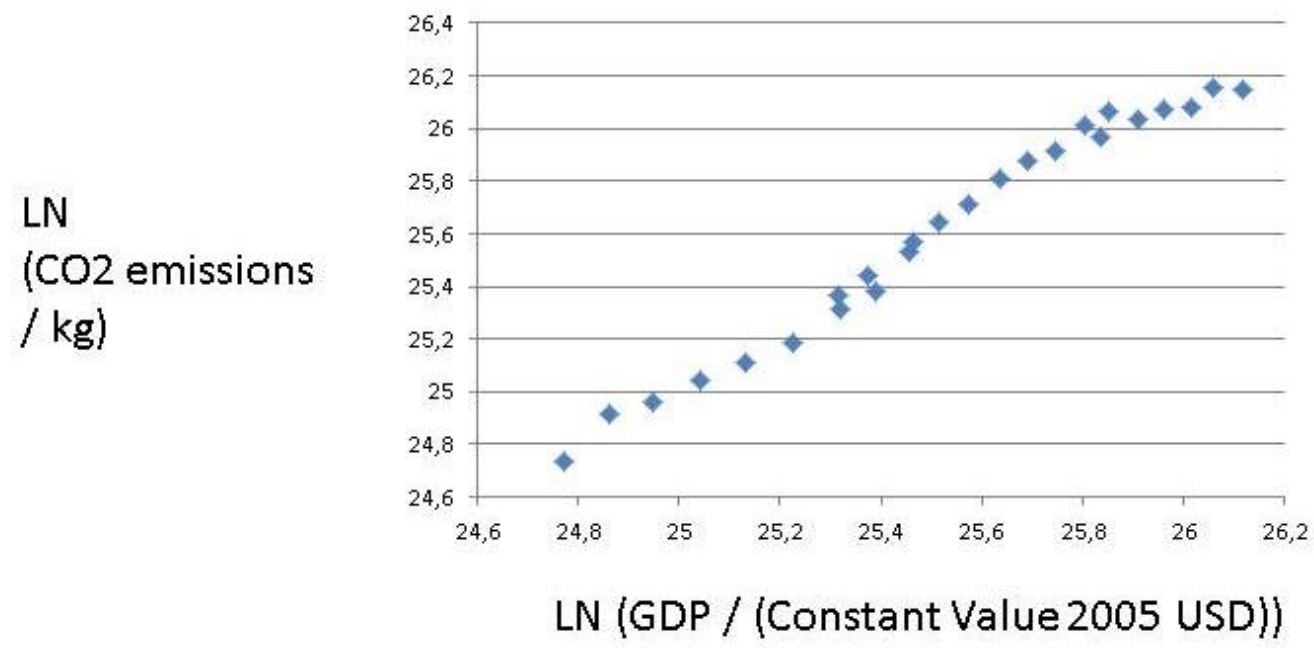

Figure 13. Malaysia $\left(y=1.13 x ; R^{2}=0.98\right)$

Malaysia employs energy of a very mixed bag (Figure 14), but still its emissions augment in line with economic development.

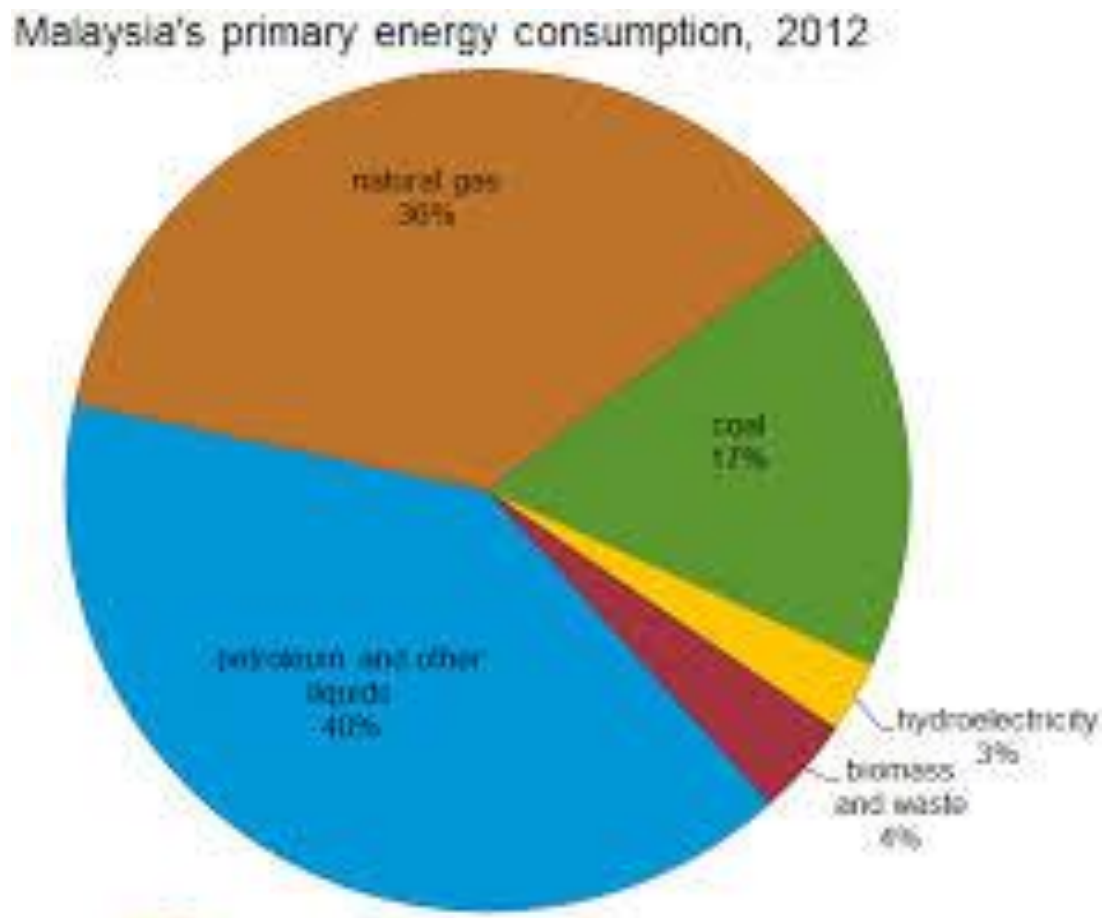

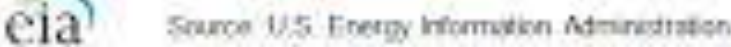

Figure 14. Malaysia's Primary Energy Consumption 
Renewables are not a major element in the energy consumption mix of Malaysia, as fossil fuels dominate, but not coal luckily. Countries may rely upon petroleum and gas mainly—see Iran (Figure 15 and Figure 16).

GDP vs. CO2 emissions Iran 1990-2014
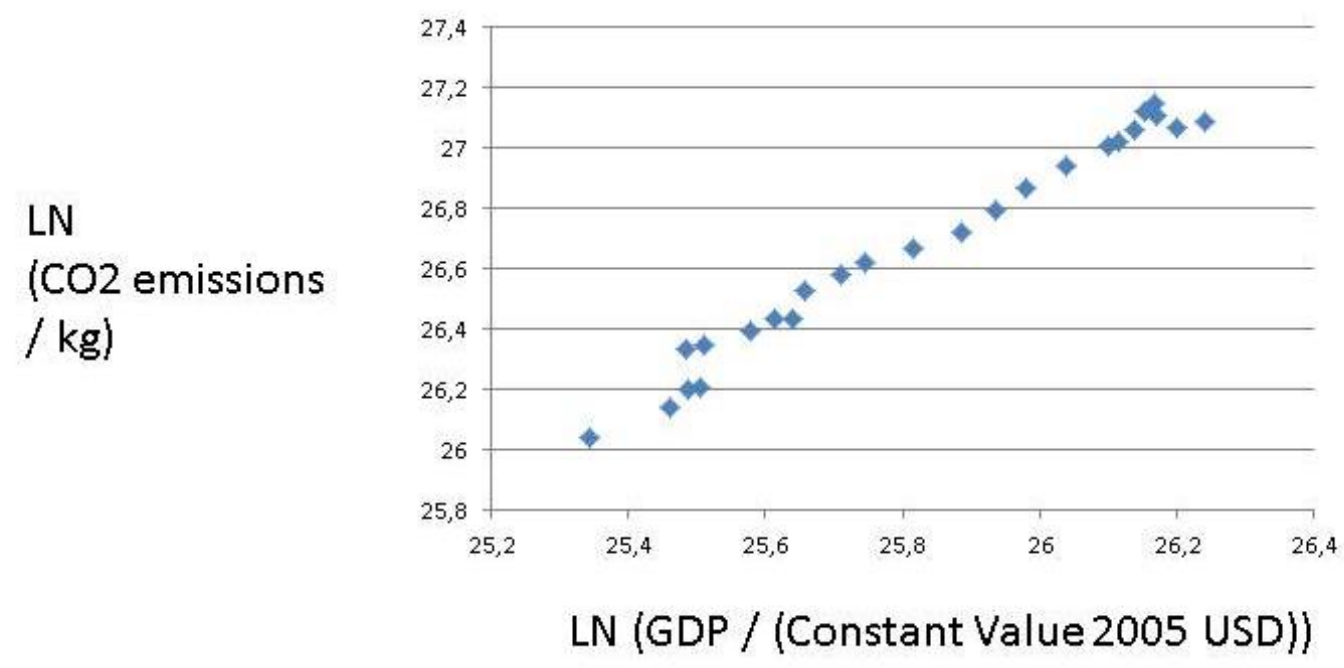

Figure 15. $\operatorname{Iran}\left(y=1.2229 x-4.91 ; R^{2}=0.98\right)$

Iran is together with Russia and Qatar the largest owner of natural gas deposits. But despite using coal in very small amounts, its $\mathrm{CO} 2$ emissions follow its GDP development. 


\section{Iran's total primary energy consumption, share by fuel, 2012}

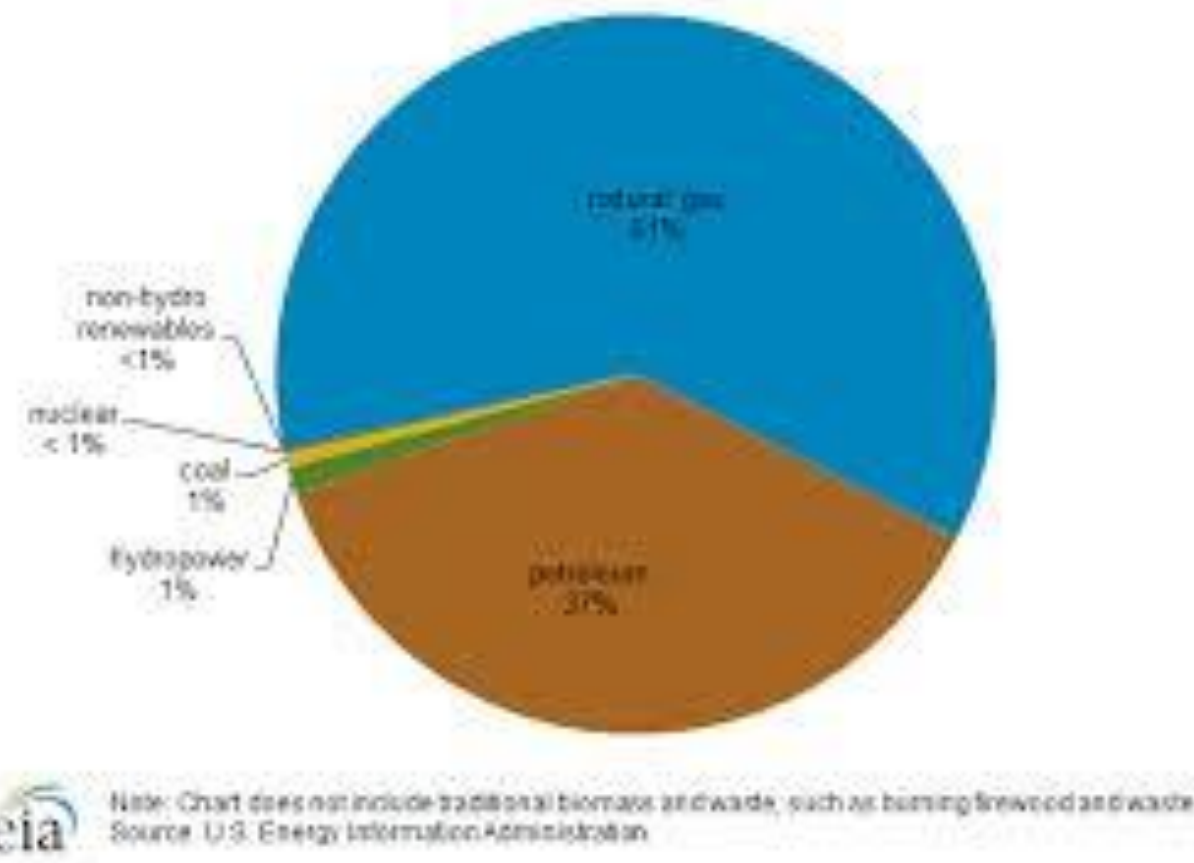

Figure 16. Iran's Total Primary Energy Consumption

Let us now look at the ethanol country par preference: Brazil. Figure 17 shows a considerable drop in total emissions, but it is followed by huge increases that tend to flatten out.

\section{GDP-CO2 emissions Brazil} $1990-2014$

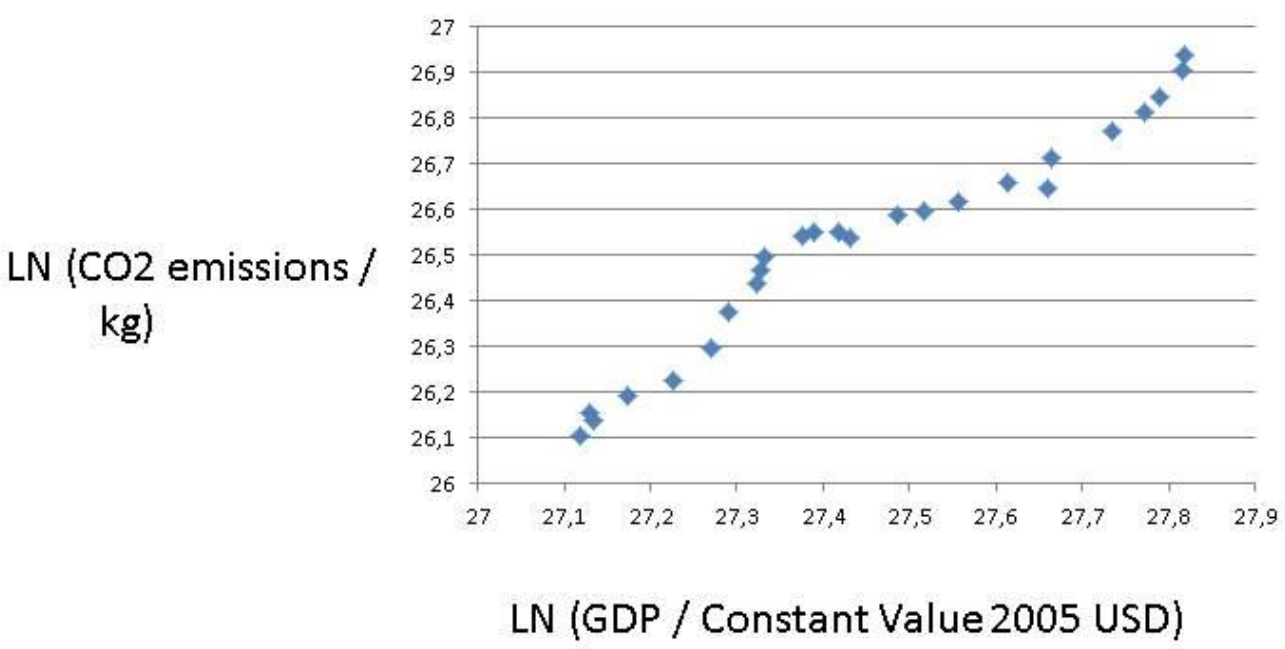

Figure 17. Brazil: LN (CO2/Kg and LN (GDP/Constant Value 2005 USD) $\left(y=1.029 x-1.72 ; R^{2}=\right.$ 0.95) 
Brazil employs the most biomass in the world, but the emissions stay at a high level, which is a reminder that renewables may also have $\mathrm{CO} 2$ :s. One advantage for Brazil is the large component of hydro power, but the overall picture for the largest Latin American country is not wholly promising when it comes to reduction of emissions. Global warming reduces the potential of hydro power, and Brazil has very little nuclear power (Figure 18).

\section{Brazil energy consumption 2013}

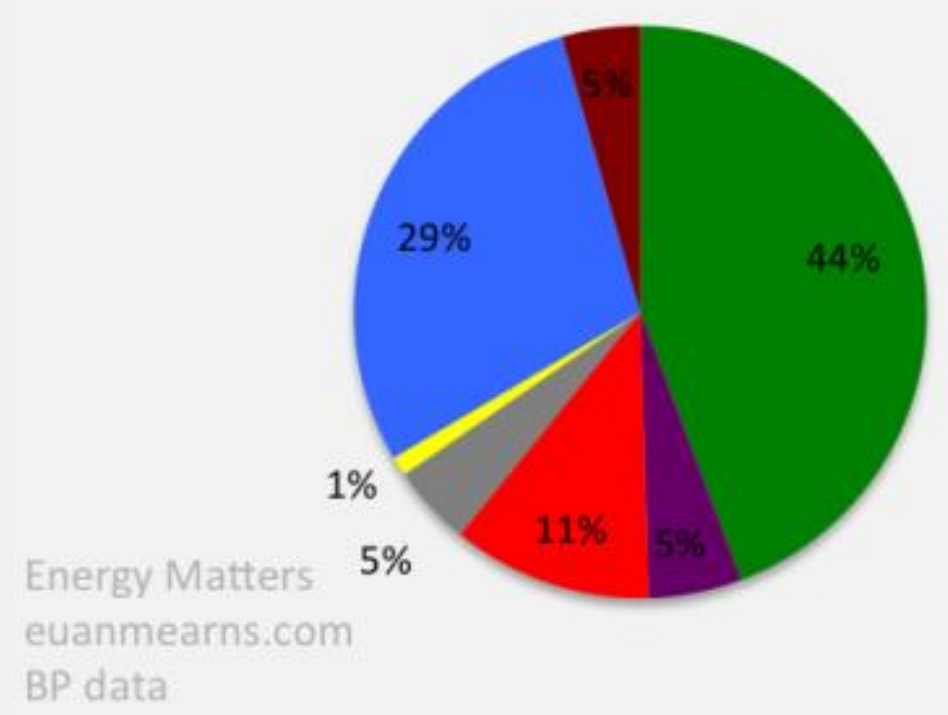

- Oil

- Biofuel

Gas

Coal

Nuclear

Hydro

Renewables

Figure 18. Brazil Energy Consumption

One may find a close link between GDP and emissions also in countries with an advanced economy. See Figure 19 for South Korea. 


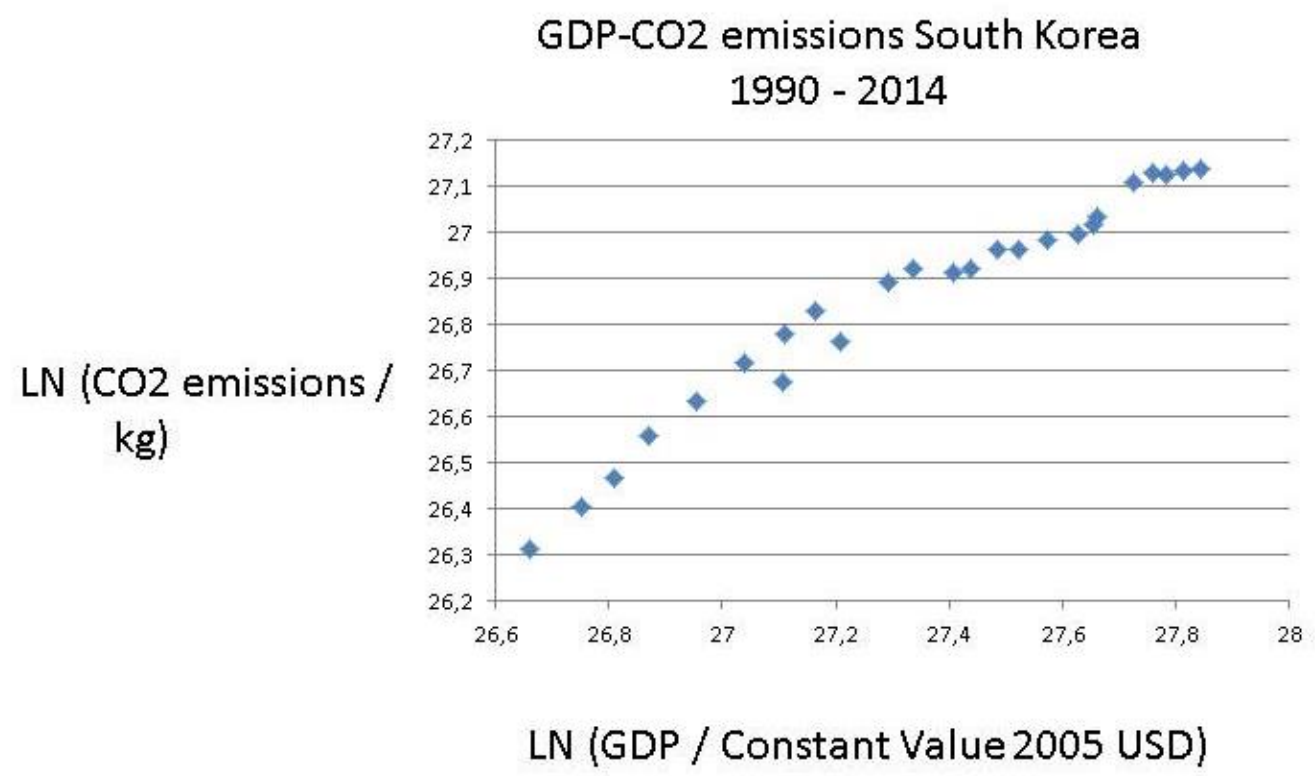

Figure 19. South Korea: LN (CO2/Kg and LN (GDP/Constant Value 2005 USD) $(y=0.65 x+9.19$;

$$
\mathbf{R}^{2}=\mathbf{0 . 9 6 )}
$$

\section{South Korea total primary energy consumption} by fuel type, 2012

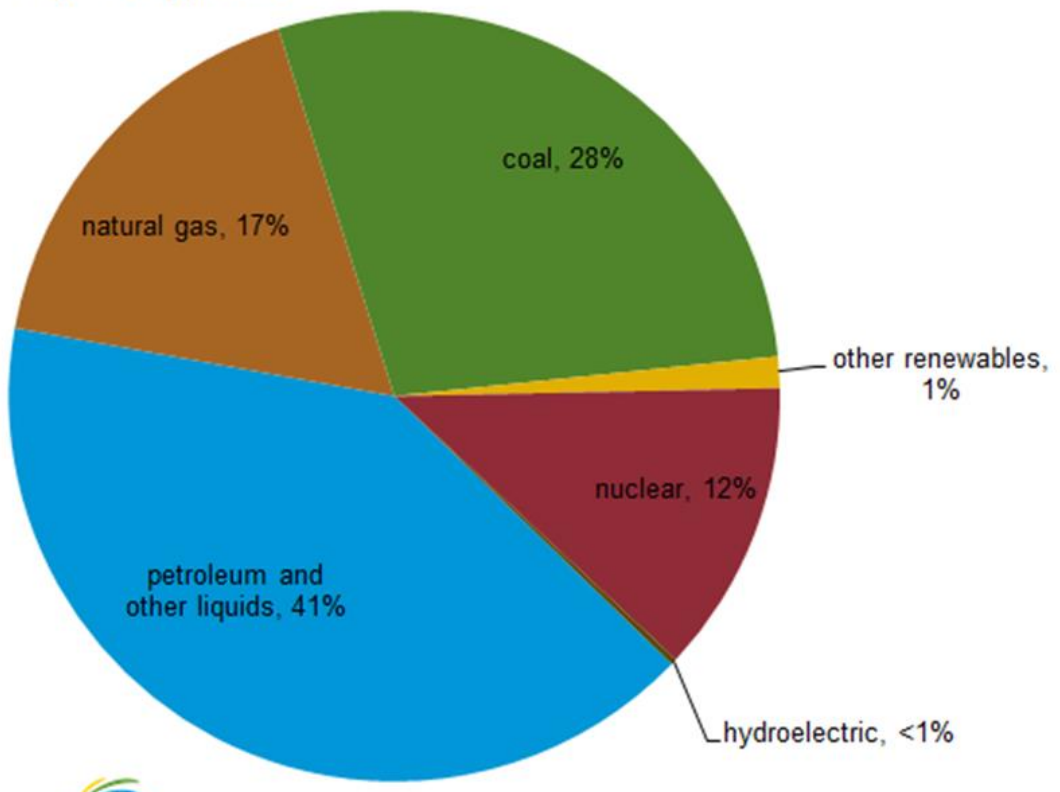

eia Source: U.S. Energy Information Administration

Figure 20. South Korea Total Primary Energy Consumption

Lacking much hydro power, South Korea has turned to fossil fuels for energy purposes, almost up to 90 per cent (Figure 20). It differs from China only in the reliance upon nuclear power, where the country is 
a world leader in plant constructions. Reducing its hefty $\mathrm{CO} 2$ emissions, South Korea will have to rely more upon renewable energy sources, as well as reducing coal and oil for imported gas or LNGs.

Among the above countries that are giant polluters in terms of $\mathrm{CO} 2$, China and South Korea uses mainly fossil fuels for energy consumption, whereas India also employs renewables and hydro power, lacking in the other two countries.

\section{A Few Developed Countries}

Although Canada is a major emitter of $\mathrm{CO} 2 \mathrm{~s}$ as well as one of the world's largest fossil fuel producer-oil sands, it has managed to stem the increase in emissions for the most recent years, i.e., halting the augmentation (Figure 21). Figure 22 may be invoked to explain this, showing a very mixed energy consumption pattern.

GDP-CO2 emissions Canada 1990 - 2014

$\mathrm{LN}$ (CO2 emissions ) $\mathrm{kg})$

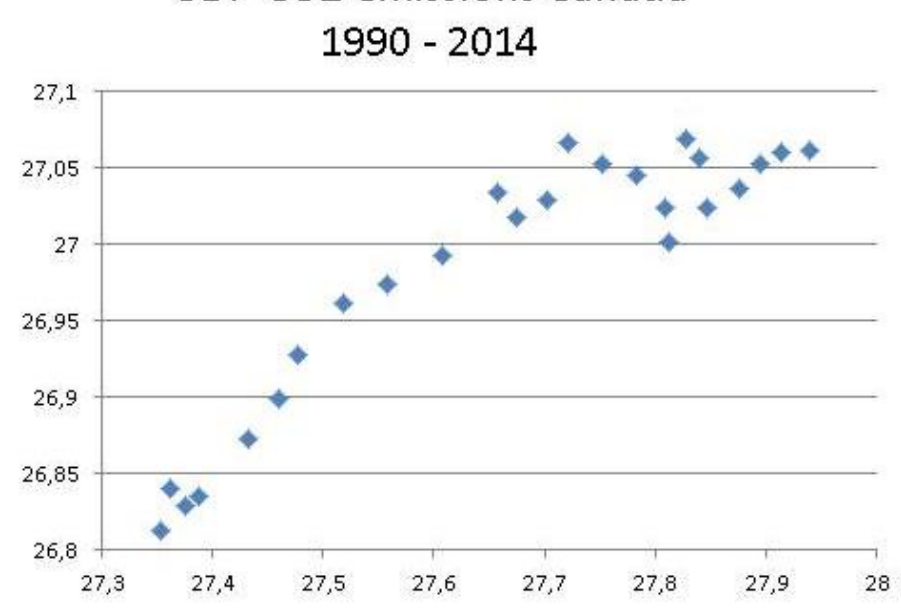

LN (GDP / Constant Value 2005 USD)

Figure 21. Canada: LN (CO2/Kg and LN (GDP/Constant Value 2005 USD) $\left(y=0.41 x+15.7 ; R^{2}=\right.$ 0.85) 


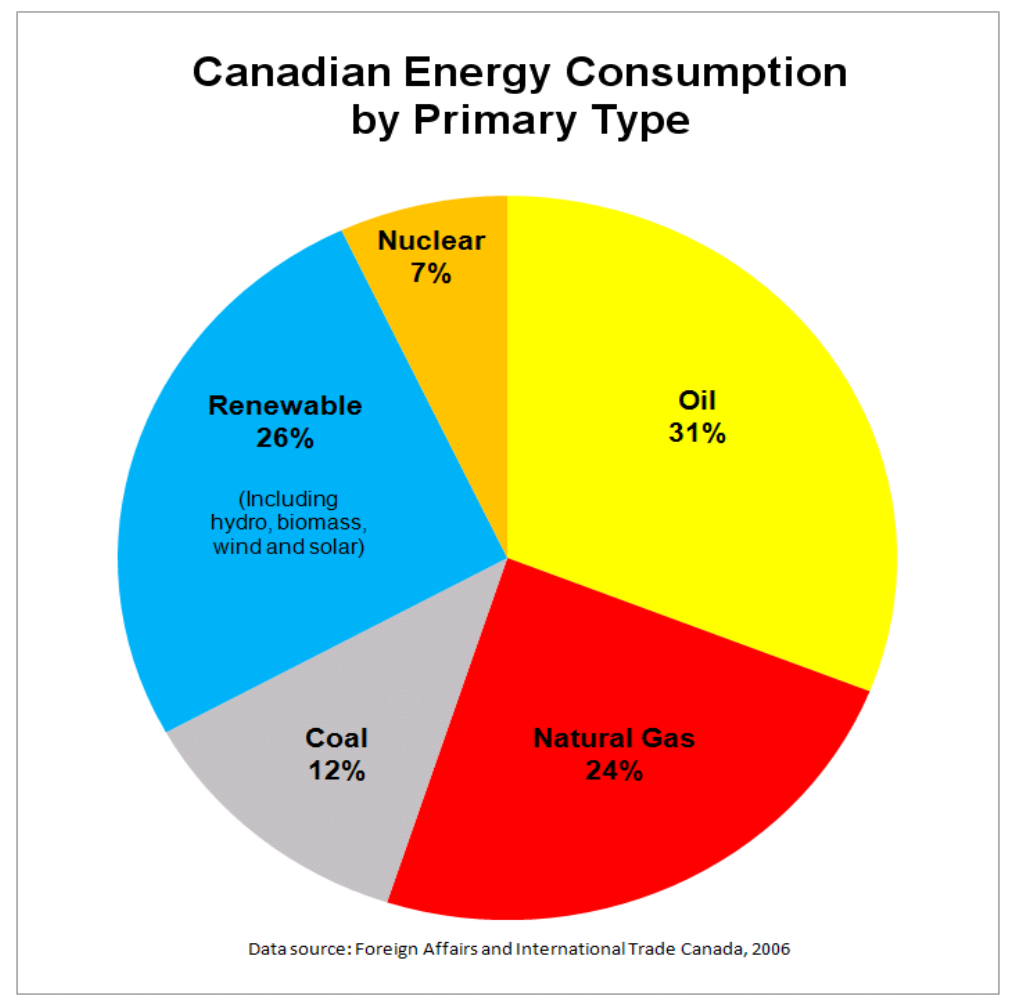

Figure 22. Canadian Energy Consumption

Canada has a strong advantage compared with for instance China and India in that it has access to lots of hydro power and natural gas. The burning of coal is as low as 12 per cent, but oil still makes up almost a third of energy consumption.

For most countries hold that their emission of $\mathrm{CO} 2$ :s increases, as well as augments with the GDP. However, there are a few notable exceptions of decreases that are worth mentioning. We start with the US (Figure 23). 


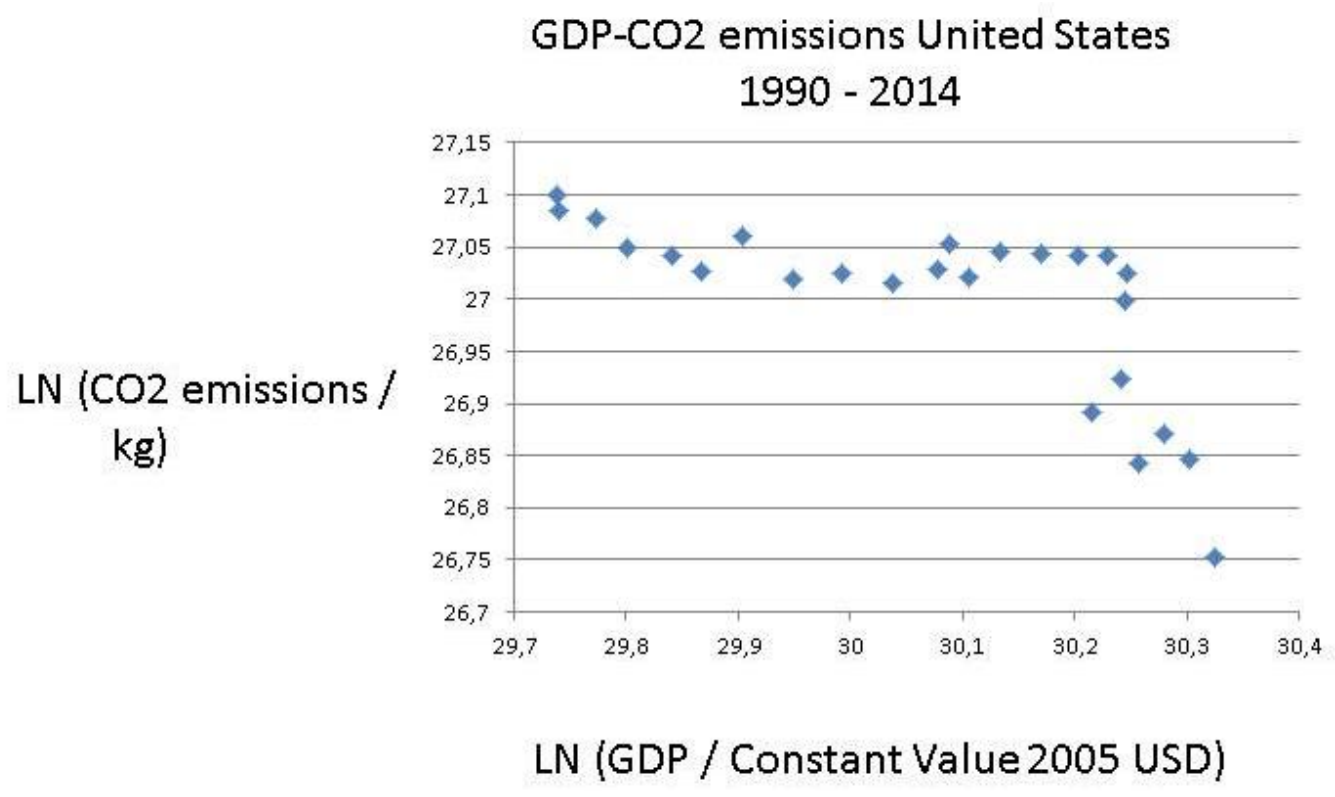

Figure 23. USA: LN (CO2/Kg and LN (GDP/Constant Value 2005 USD) $\left(y=-0.32 x+36.7 ; \mathbf{R}^{2}=\right.$ 0.49)

Recently, the level of $\mathrm{CO} 2$ emission has been reduced significantly in the US. It reflects no doubt partly the economic crisis that began 2007, but the US remains the second largest polluter in the world, reflecting that it can draw upon a mixed bag of energies only to some extent (Figure 24). Per capita $\mathrm{CO} 2$ :s is of course very high for the USA. As the economy now starts to accelerate, emissions are bound to go up again, unless solar power stations multiply over the country. 


\section{U.S. Energy Consumption by Energy Source, 2011}

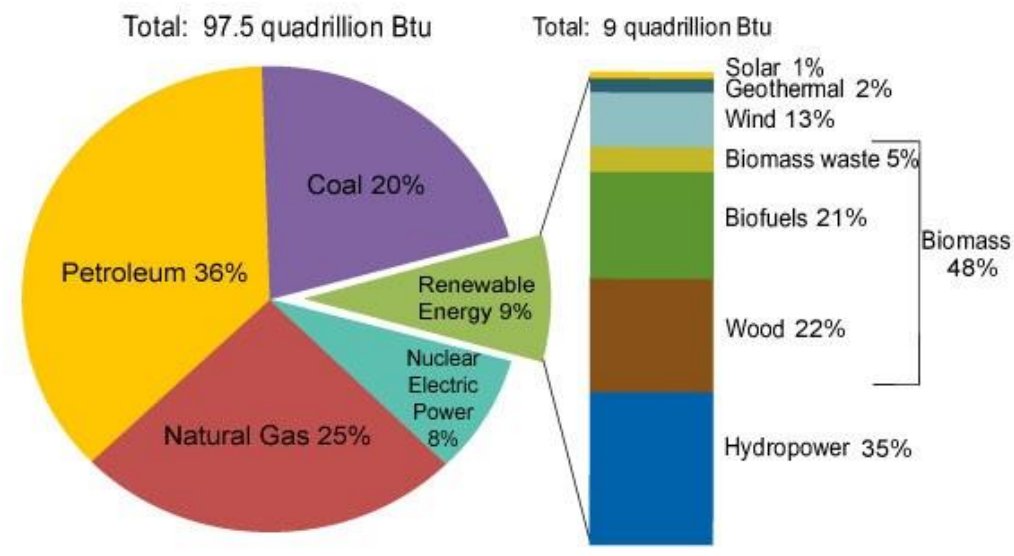

Source: U.S. Energy Information Administration, Monthly Energy Review, Table 10.1 (March 2012), preliminary 2011 data.

Figure 24. U.S. Energy Consumption

The US is heavily dependent upon fossil fuels, or some 89 per cent comes there from. What is changing is the more and more of energy is produced within the US and no longer imported from outside - the shake oil and gas revolution. Further reduction of $\mathrm{CO} 2$ :s will meet with firm resistance from the Republican House of Congress, which may oppose the COP21 Agreement. The advent of shale oil and gas has changed the entire energy markets, lowering the price of oil most substantially. This implies not only that there will be no Hubbert peak oil for the world, but also that switching to renewable energy source will be extremely expensive, relatively speaking compared with shale oil and gas.

Another interesting country is the largest EU economy, namely Germany. Figure 25 shows a marked decrease in $\mathrm{CO} 2$ emissions. 


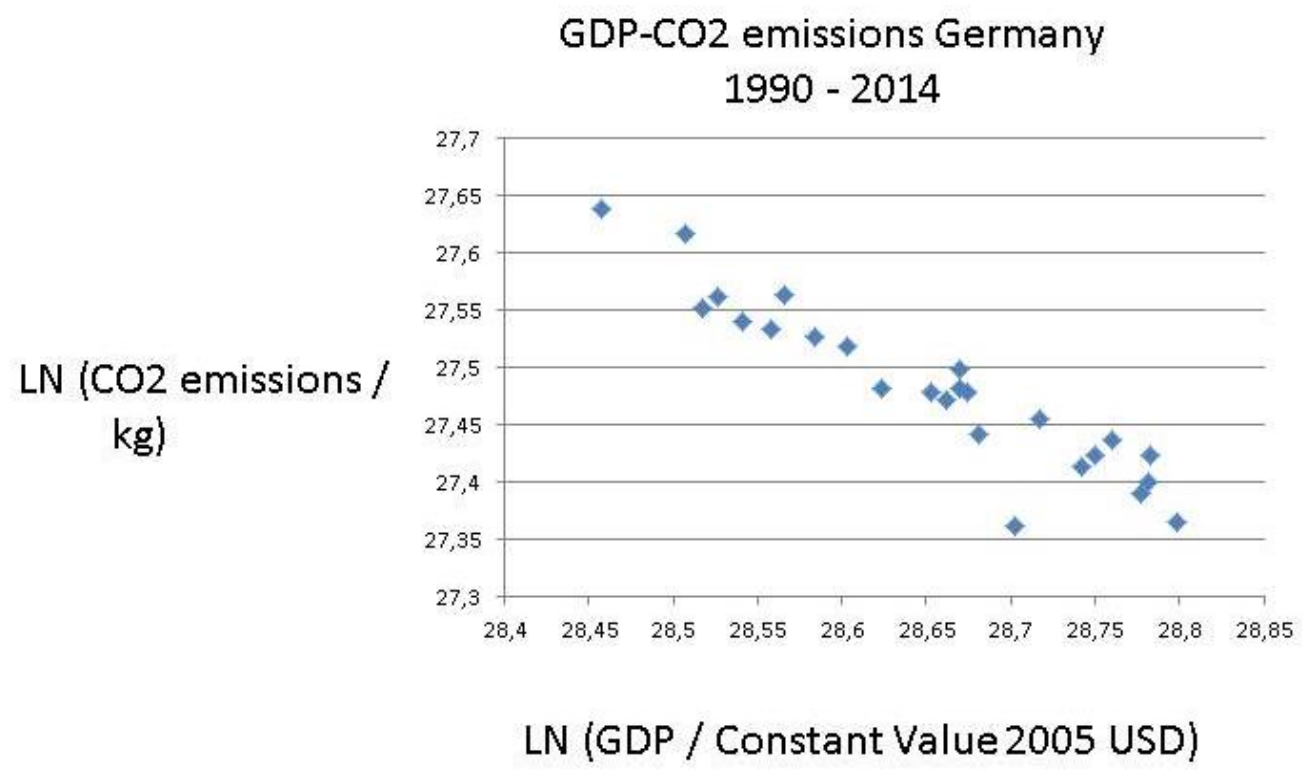

Figure 25. Germany: LN (CO2/Kg and LN (GDP/Constant Value 2005 USD) $(y=-0.69 x+47.3$;

$$
\left.\mathbf{R}^{2}=\mathbf{0 . 8 8}\right)
$$

The German data shows an impressively consistent decreasing trend, which is not to be found with many countries, if at all. How come this German exceptionalism? Germany needs massive amounts of energy, but it decided to phase out nuclear power. Can really the domestic employment of renewables satisfy this giant's demand for energy (Figure 26)? 


\section{Germany energy consumption 2012}

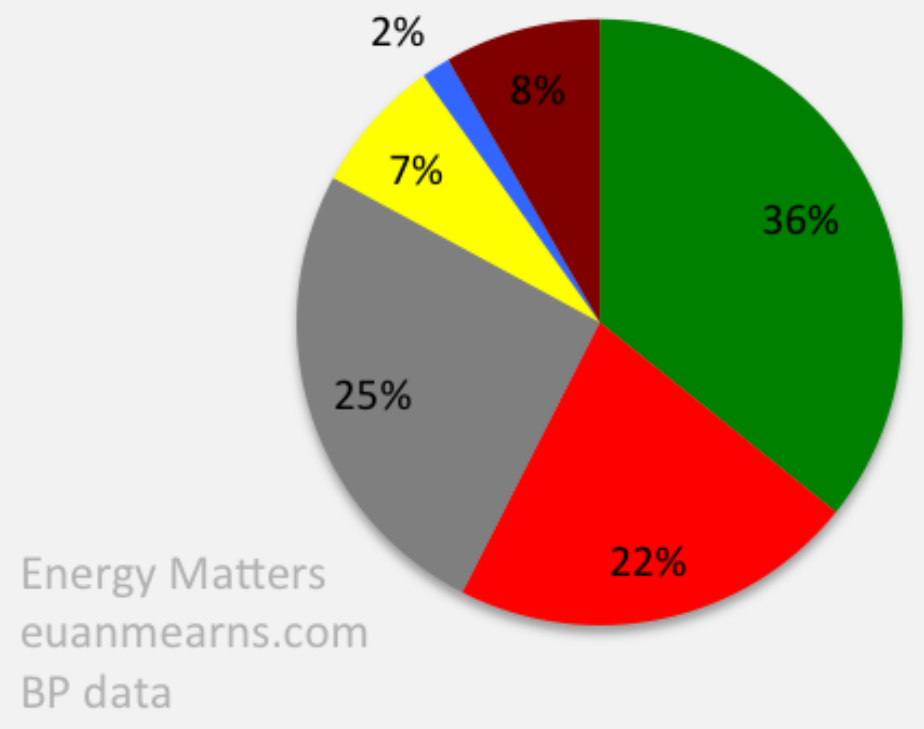

Oil

Gas

Coal

Nuclear

Hydro

Renewables

Figure 26. Germany Energy Consumption

It is true that nuclear power and renewables has made it possible for Germany to decrease its CO2:s, but the country is still dependent upon fossil fuels, especially coal and oil. What will happen with the nuclear power stations are phased out in 2022 is that most likely the CO2 emissions will start going up again. To replace nuclear power with solar and wind power on a truly massive scale will be difficult to say the least. Already, Germany uses more coal from Columbia and gas from Russia.

Interestingly, France has like Germany managed decarbonisation to some extent (Figure 27). It reflects its unique energy mix, relying much upon nuclear power. 


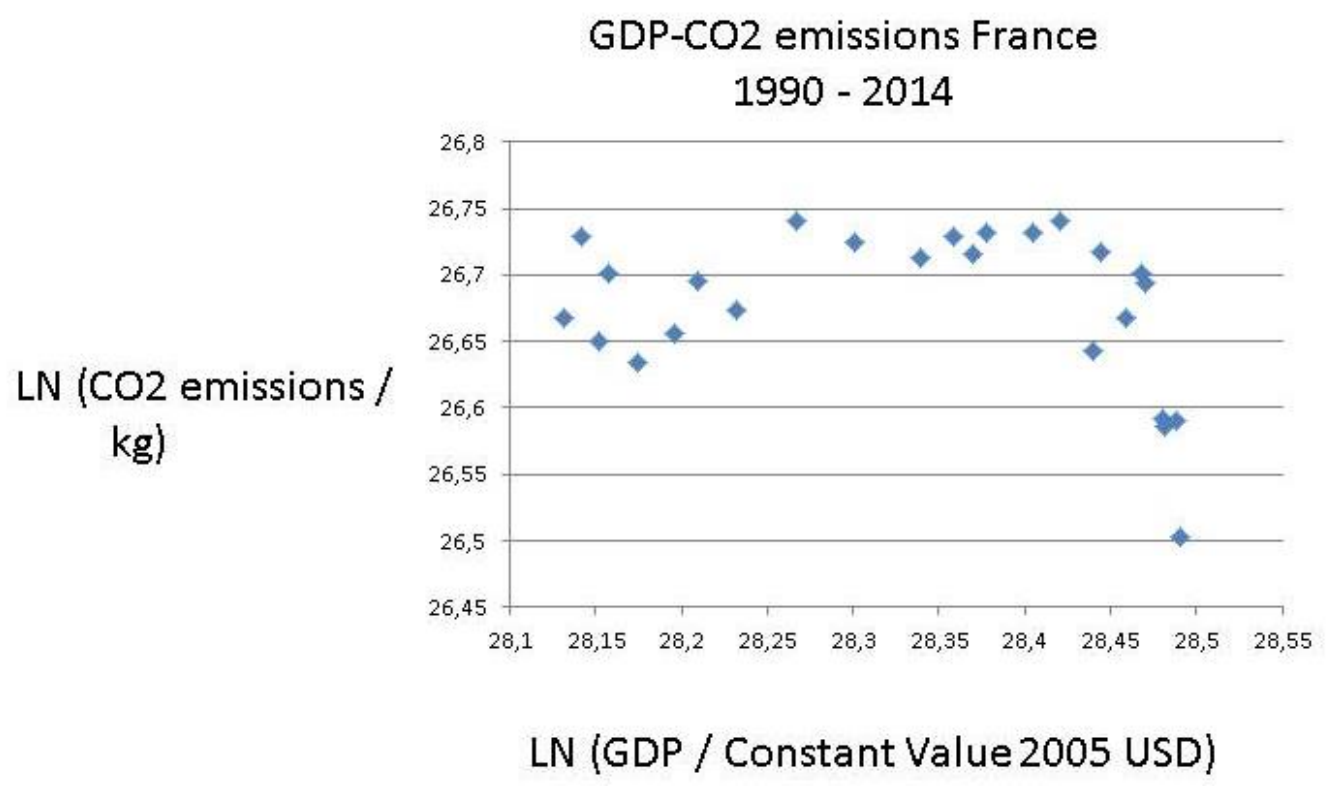

Figure 27. France $\left(y=-0.13 x+30.4 ; R^{2}=0.08\right)$

Yet, France has decided to diminish its reliance upon nuclear power. But how will it be replaced by other sources of energy?

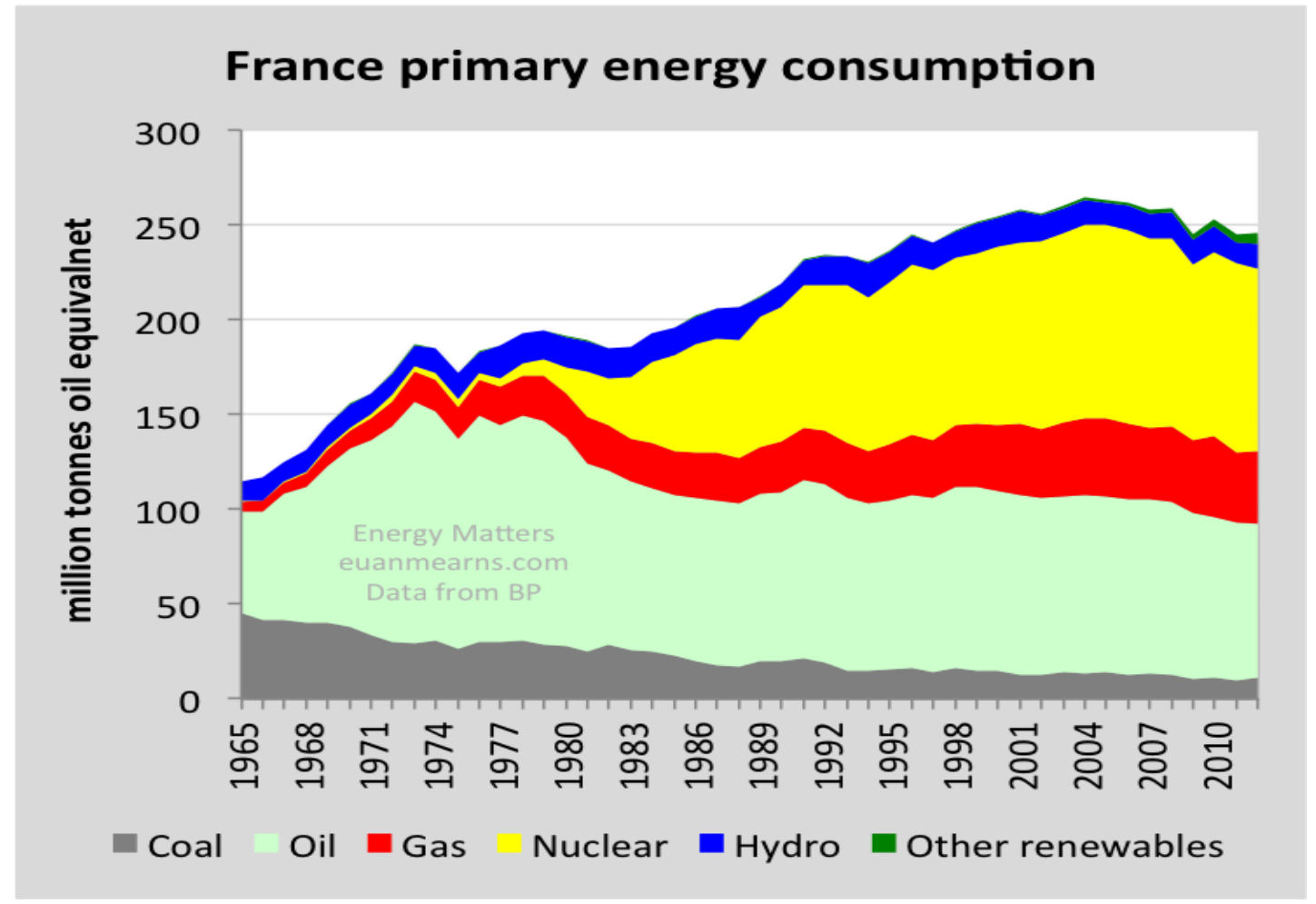

Figure 28. France Primary Energy Consumption 
No other country in the world employs nuclear power to such an extent (Figure 28). But the Green movement's criticism of nuclear power is based upon entirely different argument than the wish to decarbonise economy and society. Actually, doing both—decarbonisation and de-nuclearisation-may prove difficult for France.

\section{Gulf States}

The states around the Persian Gulf — kingdoms and emirates - have advanced economies, producing large amounts of CO2:s - see Figure 29 for Saudi Arabia. However, they also wish to demonstrate a green ambition.

GDP-CO2 emissions Saudi Arabia $1990-2014$

LN (CO2 emissions / $\mathrm{kg})$

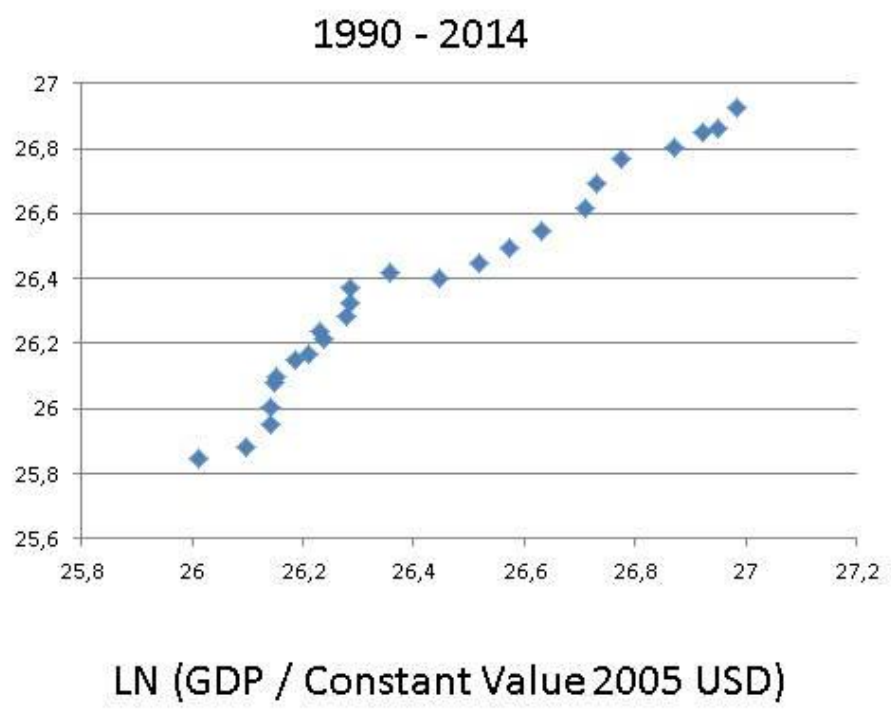

Figure 29. Saudi Arabia $\left(y=1.03 x-0.77 ; R^{2}=0.95\right)$

The Saudis like the Emirates rely upon two kinds of fossil fuels, oil and gas (Figure 30). And they use lots of cement for their magnificent buildings. 


\section{Total Energy Consumption in Saudi Arabia, by Type}

(2008)

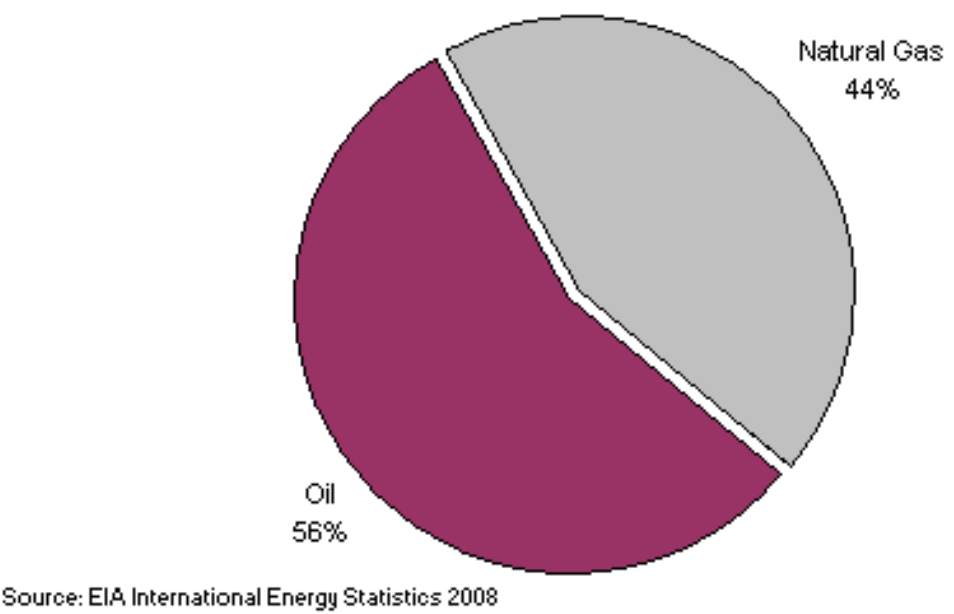

Figure 30. Total Energy Consumption in Saudi Arabia

Moreover, the UAE have increased their emission of $\mathrm{CO} 2$ sharply in relation the positive economic development of these emirates. They rely upon the fossil fuels of Abu Dhabi with immense oil resources. Like other Gulf States, the UAE boosts with building entirely GREEN sites, with energy from solar power and almost no waste. But it is based upon their enormous consumption of electricity generated out of burning oil and gas (Figure 31).

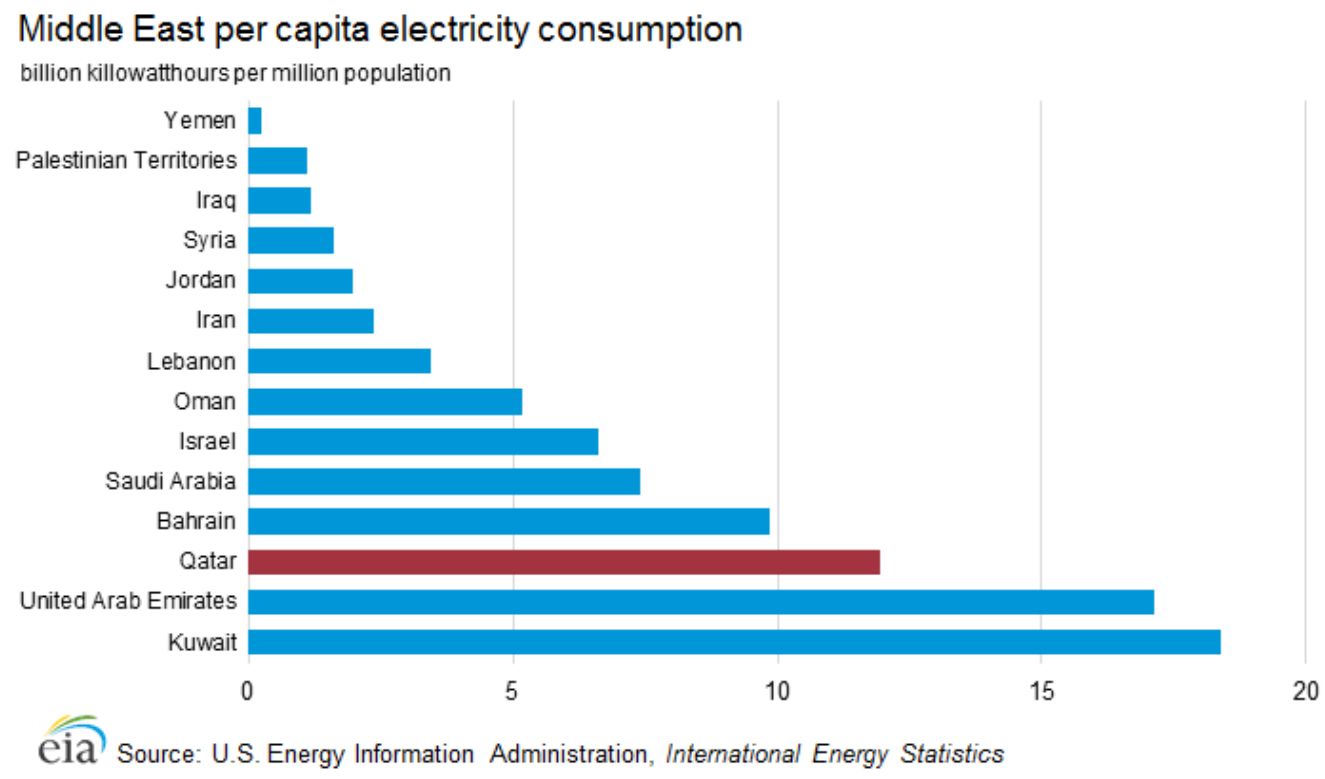

Figure 31. Middle East per Capita Electricity Consumption 
The Gulf countries use lots of petrol, gas and electricity to uphold a stunningly high standard of living, which also results in extremely high levels of emissions per capita.

\section{Conclusion}

Prospects for decarbonisation to meet COP21 objectives appear slim, as the overwhelming number of countries in the world displays the upward trend for the emission of $\mathrm{CO} 2$ :s. Only a few have managed to halt this progression, linked otherwise closely to economic development. But very few have embarked on a path of credible path of diminishing these emissions. The great developing countries are still heavily dependent upon fossil fuels. It is true that hydro power as well as wind and nuclear power are employed in some countries, but a needed huge increase in these power sources cannot be expected. Wind and solar power are still in infancy. Biomass has been resorted to on a large scale in a few countries, but it is not carbon neutral.

When discussing the major objective of halting global warming at +2 , in order to avoid +4 or catastrophically +6 , a lot of measures are mentioned: carbon capture and sequestration or carbon sucking, carbon tax, support for new technologies and innovations, huge solar plants, massive wind power stations, wave energy, etc. But people forget that energy consumption is steadily going up, as global population increases and the quest for a high level life style is shared by more and more millions of people. What is gained on one side-decarbonisation, energy efficiency, small scale solar and wind power-may simply be cancelled out by what is lost on the other side: dismantling of nuclear power, expansion of car transportation, SUV:s, etc.

Returning to Sachs, one can only say that decarbonisation will be hard to come by, especially for countries with little hydro or nuclear power. When the requirements of sustainable development collide with conventional economic growth, something has to give. It is not likely that decarbonisation will trump economic development, at least not enough to avoid $+2.7,+4$ or +6 scenarios. He states: "Economic development, social inclusion and environmental sustainability are the three tenets underpinning the forthcoming post-2015 development agenda, a once in a generation opportunity to put mankind on the path to a sustainable growth model". Yet, the COP21 Agreement lacks completely information about how the major objective of +2 should be implemented, both technologically and legally.

What must be emphasized is that the implementation of the COP Agreement can only succeed if coal is significantly reduced in electricity production and petroleum decreased in transportation. However, the stylised projections point to an altogether different world in 20-30 years. When people really realise that the implementation of $\mathrm{CO} 221$ objectives could threaten their life-styles and well-being, then governments will face resistance. It seems to be an undeniable fact that economic development and growth has been based upon a massive increase in energy consumption of mainly fossil fuels that has together with deforestation resulted in the $\mathrm{CO} 2$ emissions sky-rocketing (Figure 32). Perhaps full 
decarbonisation really requires zero economic growth, which would not be accepted by the financial community inter alia? Maybe one would like to see how dangerous global warming could turn out to be before introducing a "sustainable economy?"

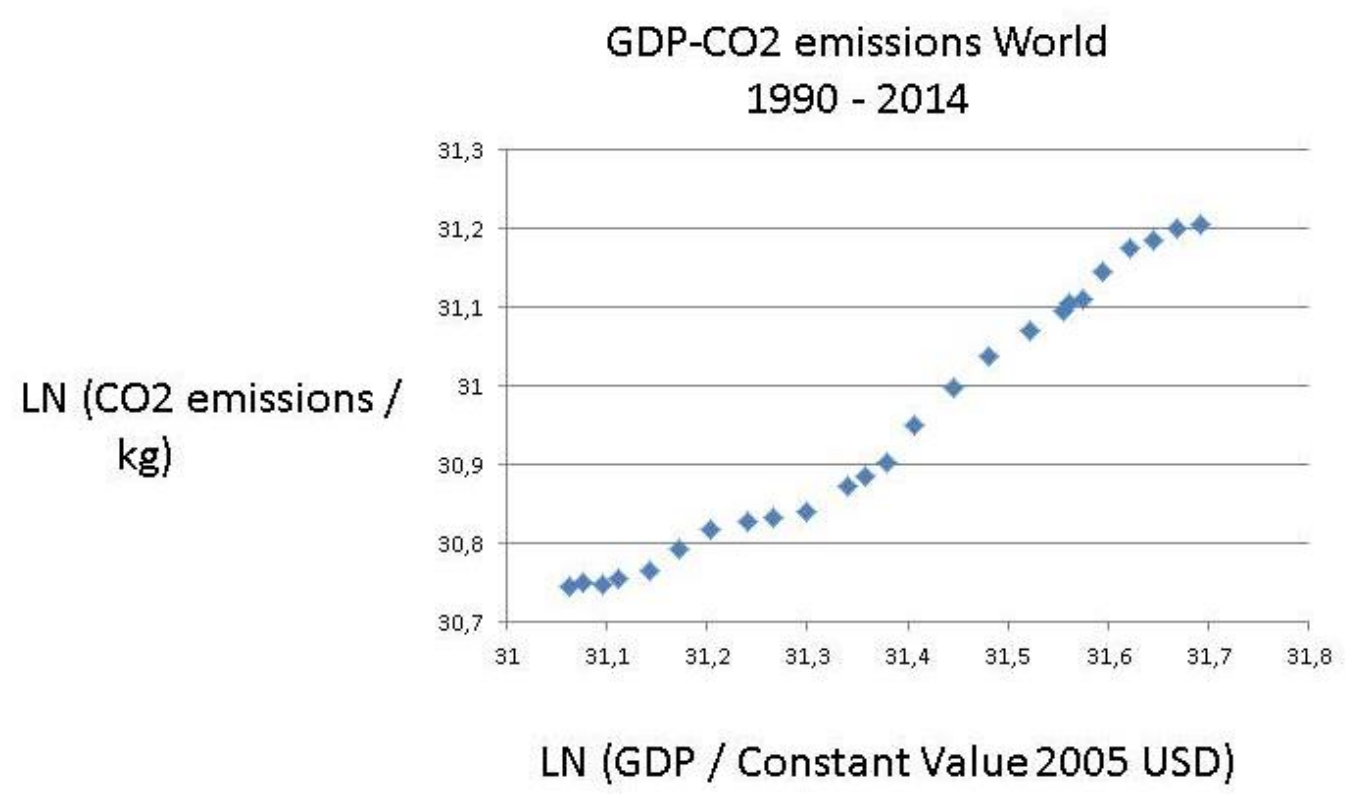

Figure 32. The World $\left(y=0.80 x+5.96 ; R^{2}=0.97\right)$

COP21 promising a decarbonisation of $40 \%$ until 2030 is not really in agreement with the major trend in the world (Figure 32), nor can it accommodate the highly optimistic projections for energy consumption in the future with an almost doubling. Something has to give, but it may not be the immense dependency upon fossil fuels. The countries above with a mixed energy bag would face less difficulties making this for mankind fundamental change, if at all feasible.

\section{Sources}

GDP:

World Bank national accounts data —http://www.data.worldbank.org

\section{OECD National Accounts data files}

CO2:

World Resources Institute CAIT Climate Data Explorer-http://www.cait.wri.org

EU Joint Research Centre Emission Database for Global Atmospheric Research—http://www.edgar.jrc.ec.europa.eu/overview.php

UN Framework Convention on Climate Change-http://www.unfccc.int/ghg_data/ghg_data_unfccc/ time_series_annex_i/items/3814.php

International Energy Agency. Paris. 
Energy Information Administration. Washington, DC.

\section{References}

Pressman, J., \& Wildavsky, A. (1973, 1984). Implementation. Berkeley: University of California Press. Sachs, J. (2015, August 10). Sustainable Development for Humanity's Future. Retrieved from http://www.jeffsachs.org/2015/08/sustainable-development-for-humanitys-future/

Stern, N. (2007). The Economics of Climate Change. Oxford: OUP. 